\title{
NAPL Occurrences at an Industrial Site: Creosote or Petroleum Hydrocarbons?
}

\author{
Jun Lu' ${ }^{1}$, Barbara Oslund ${ }^{2}$ \\ ${ }^{1}$ School of Resources and Environment, Hefei University of Technology, Hefei, China \\ ${ }^{2}$ AECOM, Morrisville, North Carolina, USA \\ Email: junlu21@yahoo.com, Barbara.Oslund@aecom.com
}

How to cite this paper: $\mathrm{Lu}, \mathrm{J}$. and Oslund, B. (2018) NAPL Occurrences at an Industrial Site: Creosote or Petroleum Hydrocarbons? Journal of Environmental Protection, 9, 581-605.

https://doi.org/10.4236/jep.2018.95037

Received: March 23, 2018

Accepted: May 28, 2018

Published: May 31, 2018

Copyright ( 92018 by authors and Scientific Research Publishing Inc. This work is licensed under the Creative Commons Attribution International License (CC BY 4.0).

http://creativecommons.org/licenses/by/4.0/

(c) (i) Open Access

\begin{abstract}
A creosote bulk storage and transfer facility operated for at least 60 years (until the early 1990's) on real estate leased from a railroad. The former facility (the Site) and surrounding properties have over a century of industrial use including large volume bulk storage of petroleum hydrocarbons such as No. 6 (heavy) fuel oil. Creosote storage occurred locally at the Site. Over the years differing non-aqueous phase liquid (NAPL) products have co-mingled on the Site, posing the need for differentiation between hydrocarbons common to both petroleum and creosote. In 2013 and 2016, known creosote source samples were collected from monitoring and recovery wells and soil. These samples were intended to provide comparison with property line locations that are potentially affected by petroleum (suspected No. 6 fuel oil) and/or creosote. Forensic analyses include GC/FID chromatograms, GC/MS biomarker analysis and extended PAH analysis. Each set of data revealed diagnostic characteristics of the products of interest. Combined with Site and surrounding facility operational history and hydrogeology, it was concluded that petroleum product (No. 6) fuel was present in property line wells and was believed to originate from the neighboring facility. The study not only supported liability allocation issues, but also contributed to understanding the dissolved phase plume characteristics.
\end{abstract}

\section{Keywords}

Creosote, No.6 Fuel Oil, Chemical Fingerprinting, Pattern Recognition, Biomarkers

\section{Introduction}

The Site was operated as a creosote and tall oil bulk rail transfer and storage fa- 
cility from the 1930s through the 1990s. The Site operator and location are confidential. The general area has had at least a century of heavy industrial use, and the Site is almost completely surrounded by a bulk petroleum and chemical storage facility with a different owner/operator. Well gauging has been conducted on the Site at least annually since 2002 and more frequently in recent years after a supplemental investigation was initiated. Dense NAPL (DNAPL), with physical characteristics similar to creosote/tall oil, has been documented in groundwater monitoring and recovery wells and sumps throughout the Site. Available operational records indicate that petroleum hydrocarbons were not in use or released on the Site.

Within the neighboring bulk storage facility, light NAPL (LNAPL) has been observed in the monitoring wells, both within the interior and near the property boundary with the Site. The operator of the bulk storage facility has previously attributed LNAPL to No. 6 fuel oil (a high-viscosity residual oil, also known as Bunker C fuel).

A measureable LNAPL layer became apparent in a shallow Site monitoring well after it was redeveloped in 2013. This well is located on the Site near the property boundary with the surrounding petroleum bulk storage facility. Because the LNAPL was uncharacteristic of the DNAPL typically observed and characterized elsewhere on the Site, a sample was first collected and analyzed in 2013 to understand whether it was attributable to petroleum or creosote. During 2016 drilling for replacement monitoring wells, NAPL seepage was observed. This seepage was located in the shallow sub-surface unsaturated soil on the top of a clay layer, adjacent to the property boundary with the bulk storage facility.

The observations noted above prompted additional sample collection and forensic study. The study objectives were to differentiate the LNAPL from DNAPL samples and to identify the characteristics indicative of petroleum hydrocarbons and/or creosote, thus providing one line of evidence to determine NAPL origin.

\section{Methods}

\subsection{Methods}

Chemical fingerprinting was employed as the primary technique to meet the objectives. Samples of LNAPL, DNAPL, and oily water were collected from the Site. Table 1 summarizes the wells from which samples were collected, submittal date, laboratory analyses, and sample collection rationale. Three types of laboratory analyses were conducted: 1) GC/FID chromatograms; 2) Extended PAH analysis and 3) GC/MS full scan including biomarker analysis.

\subsection{Gas Chromatography/Flame-Ionization Detector (GC/FID) Hydrocarbon Characterization}

GC/FID hydrocarbon characterization analysis is similar to United States Environmental Protection Agency (EPA) Method 8015, but with different objectives. It provides qualitative data for NAPL characteristics or chemical fingerprints. 
Table 1. Analytical Method Performed.

\begin{tabular}{|c|c|c|c|c|c|c|}
\hline \multirow[b]{2}{*}{$\begin{array}{c}\text { Sample } \\
\text { Identification }\end{array}$} & \multirow[b]{2}{*}{ Matrix } & \multirow[b]{2}{*}{$\begin{array}{c}\text { Sample } \\
\text { Submittal } \\
\text { Date }\end{array}$} & \multicolumn{3}{|c|}{ Analytical Method Performed } & \multirow[b]{2}{*}{ Rationale } \\
\hline & & & $\begin{array}{c}\mathrm{C}_{3}-\mathrm{C}_{44} \text { Whole } \\
\text { Oil Analysis } \\
\text { by High } \\
\text { Resolution } \\
\text { GC/FID }\end{array}$ & $\begin{array}{c}\text { Extended } \\
\text { PAH Analysis } \\
\text { Using } \\
\text { GC/MS SIM }\end{array}$ & $\begin{array}{l}\text { GC/MS } \\
\text { Full Scan }\end{array}$ & \\
\hline RS-2/2013 & Oil/Product & June 7, 2013 & $\mathrm{X}$ & $\mathrm{X}$ & & $\begin{array}{l}\text { Sample Location Expected } \\
\text { to be primarily creosote }\end{array}$ \\
\hline RS-2/2016 & Oil/Product & August 31, 2016 & $\mathrm{X}$ & $\mathbf{X}$ & $\mathbf{X}$ & Same location noted above \\
\hline RW-2 & Oil/Product & June 7, 2013 & $\mathrm{X}$ & $\mathrm{X}$ & $\mathrm{X}$ & $\begin{array}{l}\text { Sample Location Expected } \\
\text { to be primarily creosote }\end{array}$ \\
\hline MW-10D & Oil/Product & June 7, 2013 & $\mathrm{X}$ & $\mathbf{X}$ & & Property Line Sample Location \\
\hline MW-10S/2013 & Oil/Product & July 2, 2013 & & & $\mathbf{X}$ & LNAPL Sample from Property Line location \\
\hline MW-10S/2013 & Oily Water & July 2, 2013 & & $\mathrm{X}$ & & Property Line Sample Location \\
\hline MW-10S/2016 & Oily Water & August 31, 2016 & & $\mathrm{X}$ & $\mathrm{X}$ & Same location noted above \\
\hline MW-11S & Oily Water & August 31, 2016 & & $\mathrm{X}$ & $\mathrm{X}$ & Property Line Sample Location \\
\hline MW-11D & Oily Water & August 31, 2016 & & $\mathrm{X}$ & $\mathrm{X}$ & Property Line Sample Location \\
\hline MW-14RS & Oily Water & August 31, 2016 & & $\mathrm{X}$ & $\mathrm{X}$ & Property Line Sample Location \\
\hline SS-BG & Soil & August 9, 2016 & & $\mathrm{X}$ & $\mathbf{X}$ & Background Soil Location \\
\hline SS-14P & Soil & August 9, 2016 & & $\mathrm{x}$ & $\mathrm{X}$ & $\begin{array}{l}\text { Borehole location with observed } \\
\text { suspected NAPL seepage }\end{array}$ \\
\hline
\end{tabular}

Notes: $\mathrm{D}$ = deep well of co-located pair, NAPL = non-aqueous phase liquid, RS = Recovery Sump, RW = Recovery Well, $\mathrm{S}=$ shallow well of co-located pair.

The GC/FID analytical results are typically presented as chromatograms, which are essentially patterns of resolved and unresolved compounds. In this study, GC/FID chromatograms are highly diagnostic in differentiating creosote from Fuel No. 6 as they have distinctively different chromatographic patterns. Figure 1 shows an example of Fuel No. 6 (a) and creosote (b). One of the most notable differences is that there is a prominent unresolved compound mixture (UCM) in the fuel oil (Figure 1(a)); while the baseline of the chromatogram of the creosote is essentially flat (Figure $1(\mathrm{~b})$ ).

\subsection{GC/MS Full-Scan Analysis}

The GC/MS full-scan analysis provides a total ion chromatogram (TIC) and single ion current profiles. The TIC is similar to GC/FID chromatograms and can be used in a similar manner. The single ion current profiles are derived from various groups of similar compounds such as normal paraffins, alkylcyclohexanes, PAHs, and biomarkers. Among these compounds, the biomarkers are of special value in source identification and/or correlation. In this study, identification of heavy petroleum products is the objective. As these products are typically rich in biomarkers (i.e., terpanes [ion 191] and steranes [ion 217]), while creosote is not, these compounds provide positive evidence for presence of heavy petroleum products. 


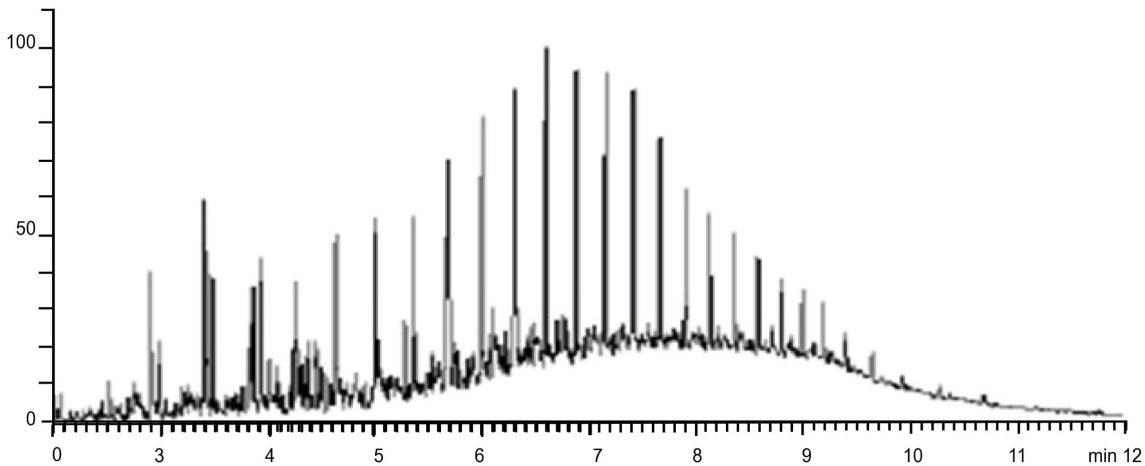

(a)

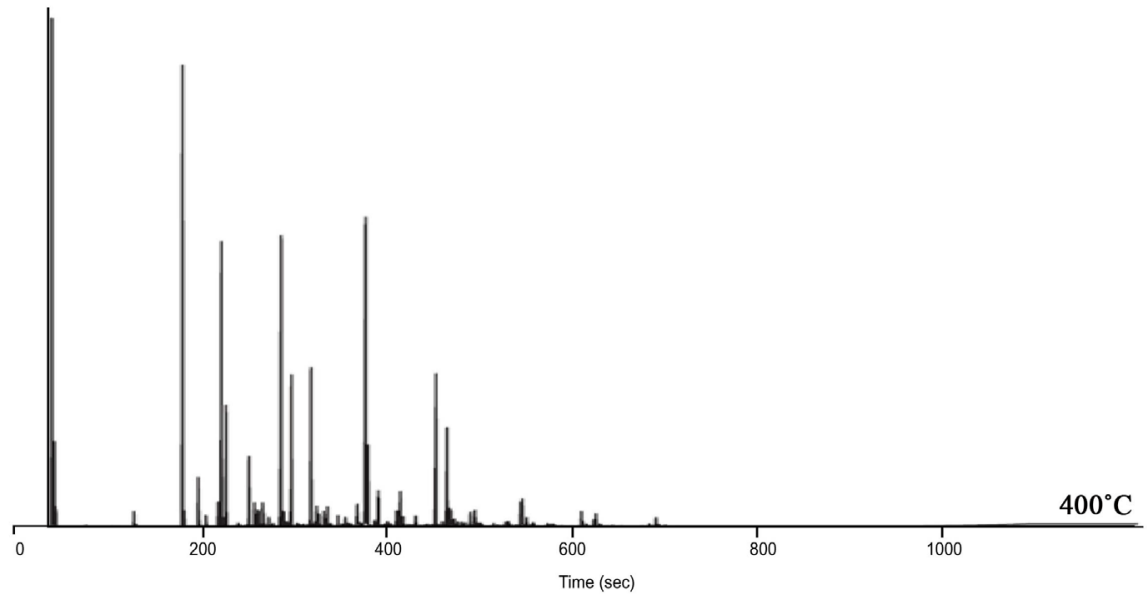

(b)

Figure 1. (a) Gas chromatograms of fuel No. 6 (Dahlmann, 2003); (b) Gas chromatograms of creosote (Restek corporation).

\subsection{Gas Chromatography/Mass Spectrometer (GC/MS) Selective Ion Method Polycyclic Aromatic Hydrocarbons (PAH) Analysis}

Extended PAH analysis generally conforms to EPA Method 8270. PAHs are a class of organic compounds consisting of two or more fused aromatic rings. This analysis quantifies concentrations of parent PAHs, alkylated PAHs, and sulfur-containing aromatics. The results are used for differentiation between pyrogenic (i.e., PAHs related to combustion such as creosote) and petrogenic (i.e., PAHs related to rock sourced/petroleum products such as Fuel No.6) sources and identification of specific sources within each general source category [1] [2] [3].

Figure 2 illustrates the differences in PAH distributions between Bunker $\mathrm{C}$ Fuel (i.e., Fuel No.6) and creosote. The homologous series of PAHs include $\mathrm{C} 0-\mathrm{C} 4$ naphthalenes, $\mathrm{C} 0-\mathrm{C} 3$ fluorenes, $\mathrm{C} 0-\mathrm{C} 4$ phenanthrenes, $\mathrm{C} 0-\mathrm{C} 4$ dibenzothiophenes, $\mathrm{C} 0-\mathrm{C} 4$ phenanthrenes/pyrenes, and $\mathrm{C} 0-\mathrm{C} 4$ chrysenes. As illustrated by Bunker $\mathrm{C}$ fuel, petrogenic materials are typically dominated by the $\mathrm{C} 2$ and $\mathrm{C} 3$ alkyl homologues (i.e., containing two and three carbon atoms attached to the parent, respectively). Within each homologue, the PAH distribution shows a 


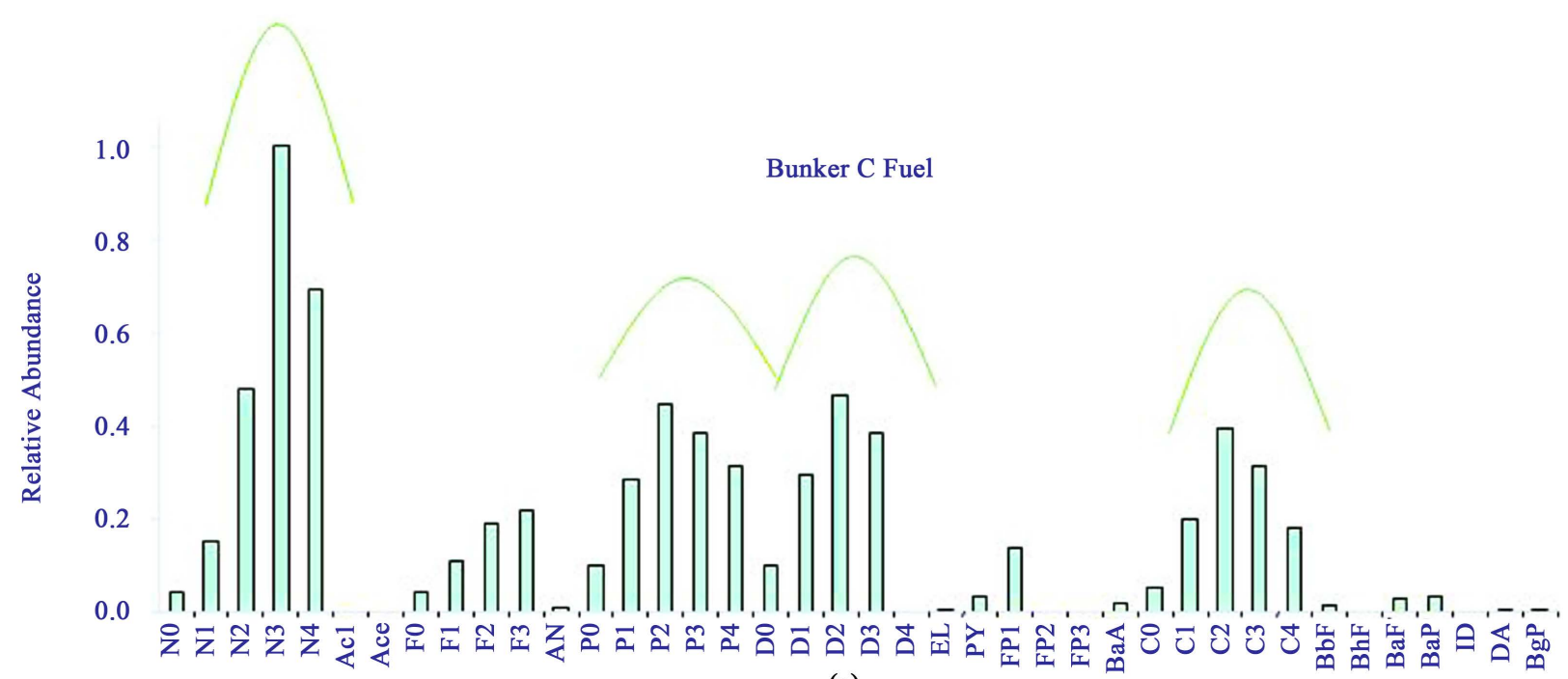

(a)

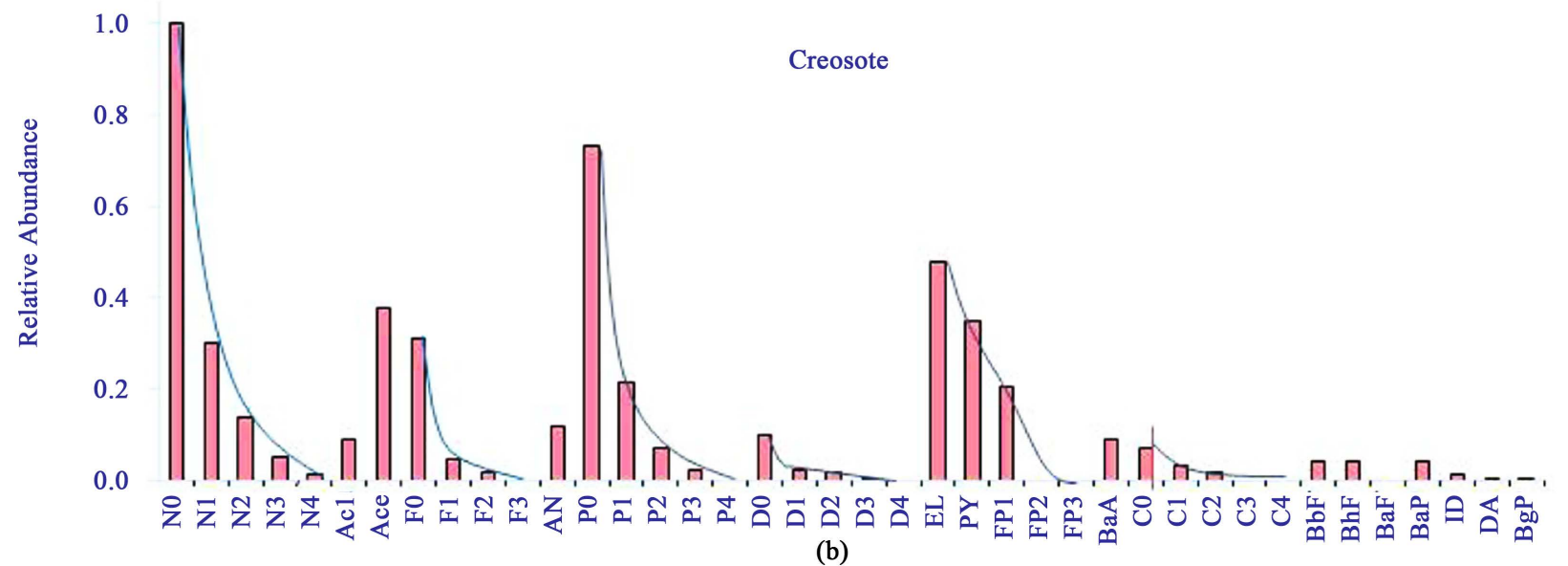

(b)

Figure 2. PAH distributions of bunker C fuel (a) and creosote (b). N: Naphthalene, F: Fluourene, P: Phenanthrene, D: Dibenzothiophene, FL: Fluoranthene, PY: Pyren, FP: Fluoranthene/Pyrene, C: Chrysene.

"bell shaped" pattern. With creosote, pyrogenic production processes result in $\mathrm{PAH}$ distributions dominated by the more thermodynamically stable parent PAHs, with the relative concentration of alkylated homologues decreasing exponentially from $\mathrm{C} 1$ to $\mathrm{C} 4$. As such, the pattern within each homologous series slopes down to the right (referred as "sloping pattern").

\section{Results}

Three sets of data were evaluated (i.e., GC/FID chromatograms or GC/MS TICs; petroleum biomarkers and alkylated PAHs) were used to chemically fingerprint the NAPL/water samples.

\subsection{GC/FID Hydrocarbon Characterization}

Four samples, RS-2/2013, RS-2/2016, RW-2, and MW-10D, were analyzed using this method, and the chromatograms are presented in Figures 3(a)-(d)), respectively. As can be observed, three chromatograms (Figures 3(a)-(c)) appear very 


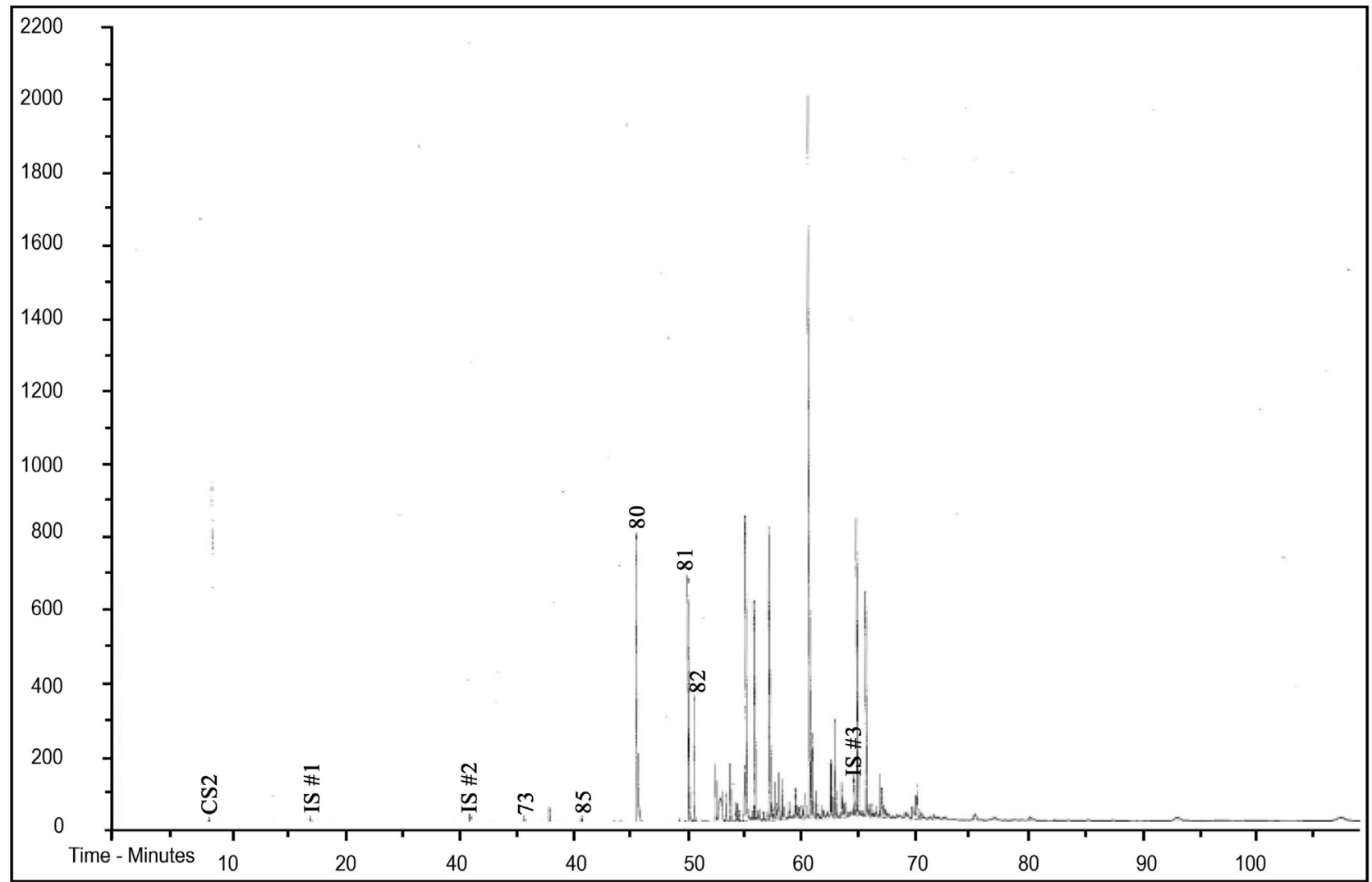

(a)

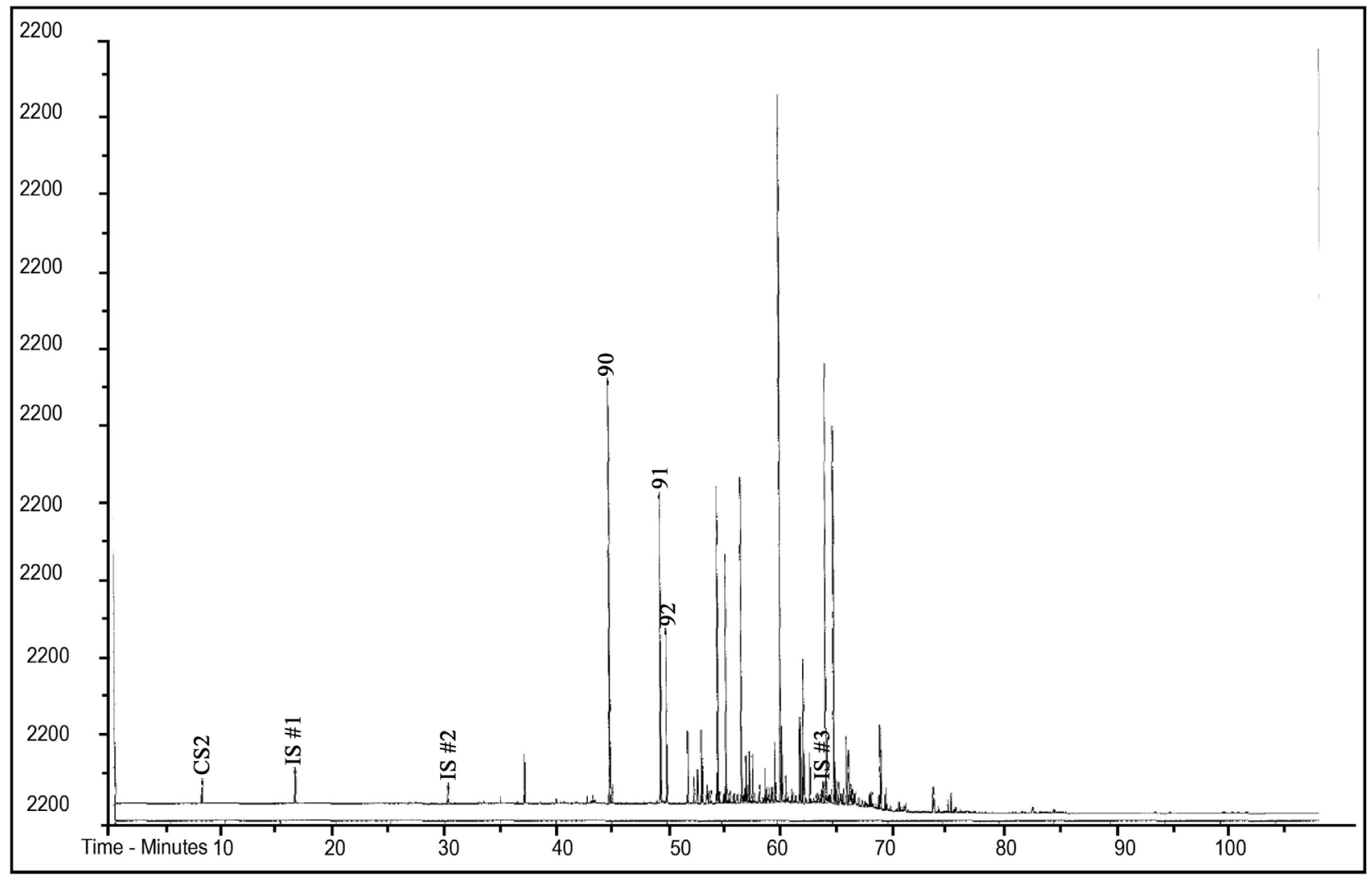

(b) 


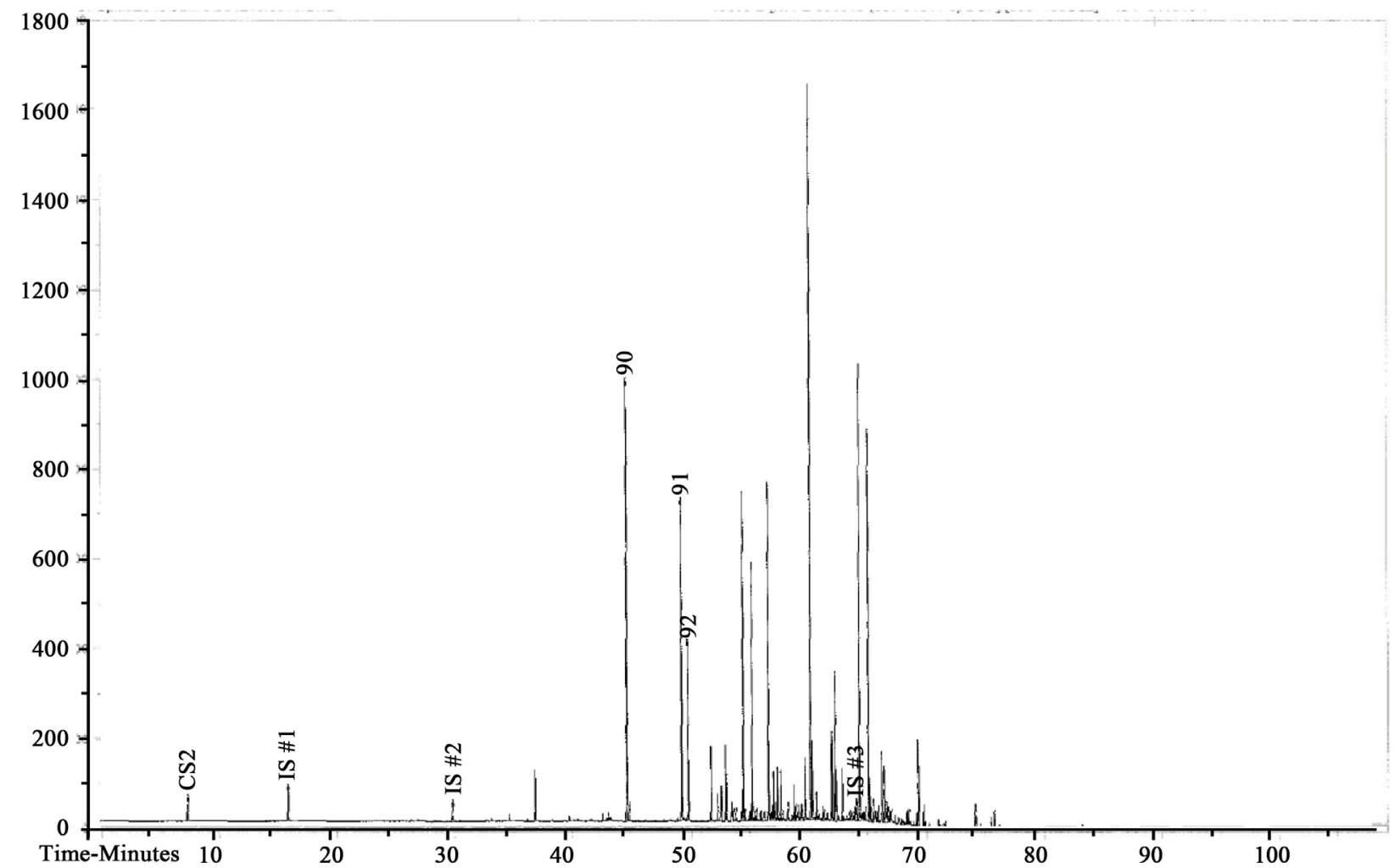

(c)

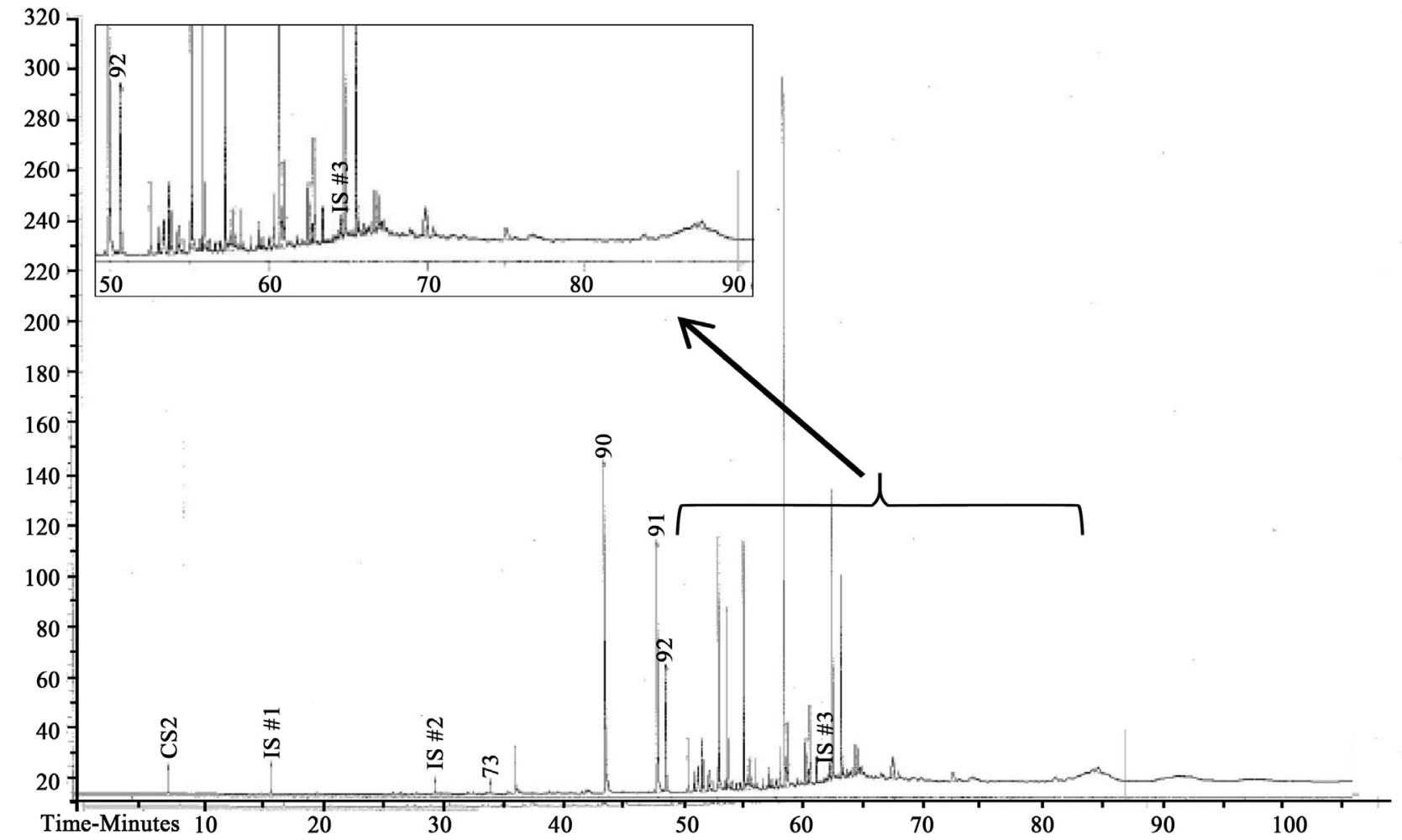

(d)

Figure 3. (a) GC/FID chromatogram of the sample RS-2/2013; (b) GC/FID chromatogram of the sample RS-2/2016; (c) GC/FID chromatogram of the sample RW-2; (d) GC/FID chromatogram of the sample MW-10D. 
similar and are characterized by a few well resolved peaks with no or negligible UCM. Based on these characteristics and site history, it appears that all three samples are creosote with no indication of petroleum based on the flat baseline (i.e., no UCM observed in these samples).

The chromatogram of sample MW-10D (Figure 3(d)) is similar to the other three samples in general. However, it was noted that a small hump appears to occur from approximately 60 minutes and continues to the end of the chromatogram. As the presence of UCM is not characteristic of the chromatogram from creosote, this hump may indicate other products (e.g., heavy petroleum products) present in the sample. It is also possible that the UCM in this sample could be due to matrix of the sample, column bleed, and baseline rise and fall. A definite reason for the UCM in this sample cannot be made with the limited GC/FID data presented.

\subsection{GC/MS Full Scan Analysis}

Nine samples (RS-2/2016, RW-2, MW-11S, MW-11D, MW-14RS, MW-10S/2013, MW-10S/2016, SS-BG, and SS-14P) were analyzed with GC/MS full-scan. In samples RS-2/2016, RW-2, MW-11S, and MW-11D, the TICs display flat baselines that are typical of creosote (Figures 4(a)-(d)), respectively). Note that for the samples RS-2/2016 and RW-2, GC/FID chromatograms are also available (Figure 3(b) and Figure 3(c)) and are consistent with GC/MS full scan TICs (Figure 4(a) and Figure 4(b)).

For the five other samples (MW-10S/2013, MW-14RS, MW-10S/2016, SS-14P, and SS-BG), the UCMs are apparent in all chromatograms (Figures 5(a)-(e), respectively), suggesting presence of petroleum products. Based on the carbon range and the peak of the UCM, the hydrocarbons from the samples MW-10S/13 and SS-14P appear similar and likely composed of Fuel No. 6. Sample MW-10S/16 (Figure 5(c)) is from the same well as MW-10S/13 (Figure 5(a)). The carbon range of the UCM is similar to that of the earlier sample; but differences are observed including lower intensity of the UCM, and more complicated patterns. Because the 2013 sample was mostly product and the 2016 sample was oily water, the differences likely resulted from the relative percentage of the "oil" and "water" in the sample and associated matrix effect.

In the sample MW-14RS (Figure 5(b)), a UCM appears to occur at earlier retention times. This sample is also an oily water sample and the apparent lighter hydrocarbons in the sample may be a lighter petroleum product (e.g., diesel \#2), the sheen from Fuel No. 6 or simply matrix effect. In the SS-BG sample (Figure $5(\mathrm{e})$ ), the peak of the UCM is at approximately 78 minutes. The hydrocarbons appear heavier than those in all other samples. The implication of this will be discussed with other data in Section 4.0.

Figures 6(a)-(d) provide an example of contrast of biomarkers between a type of heavy fuel oil and creosote. As can be observed, well-resolved biomarkers are present in the heavy petroleum product (Figure 6(a) and Figure 6(b)), while 


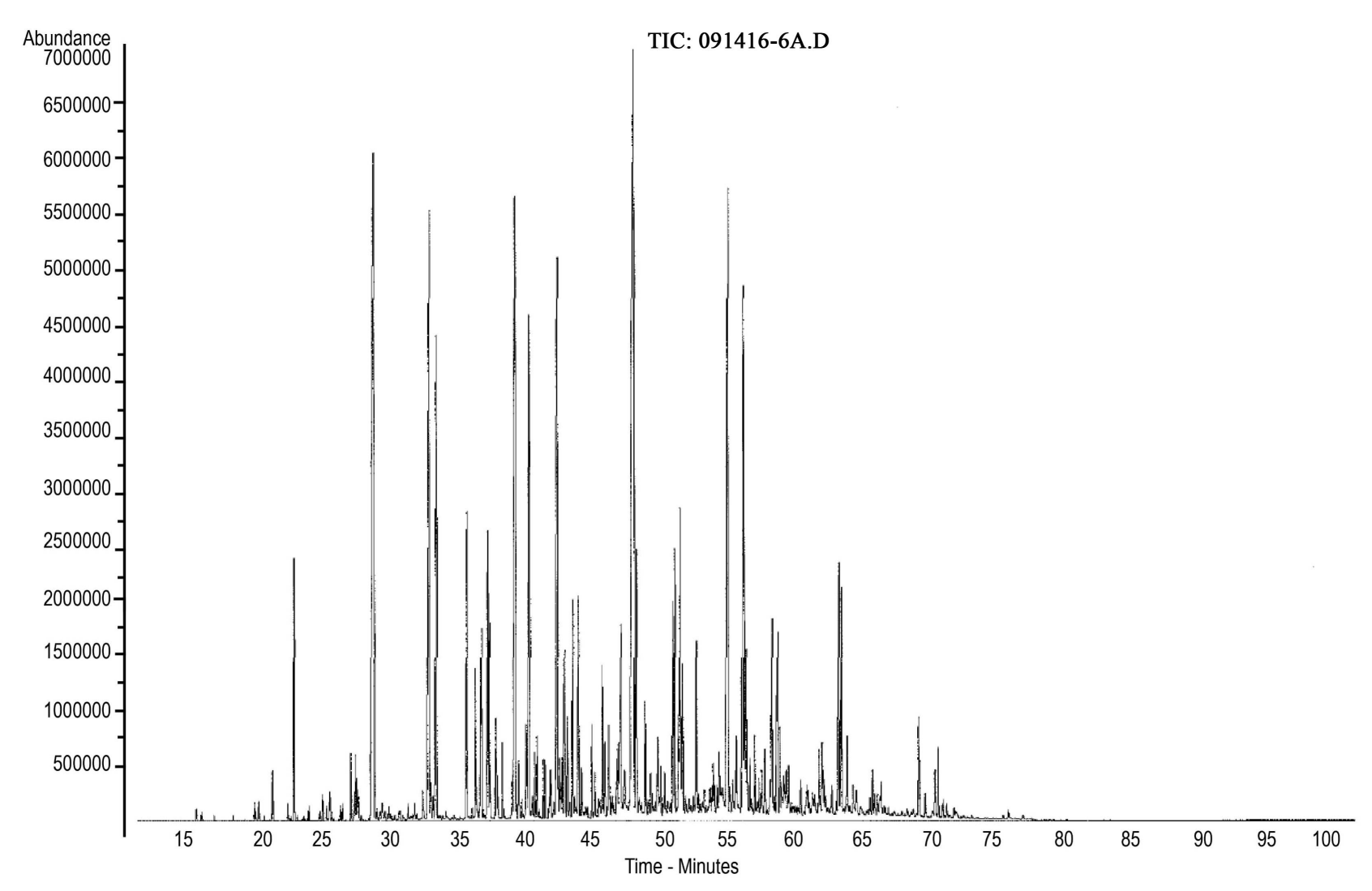

(a)

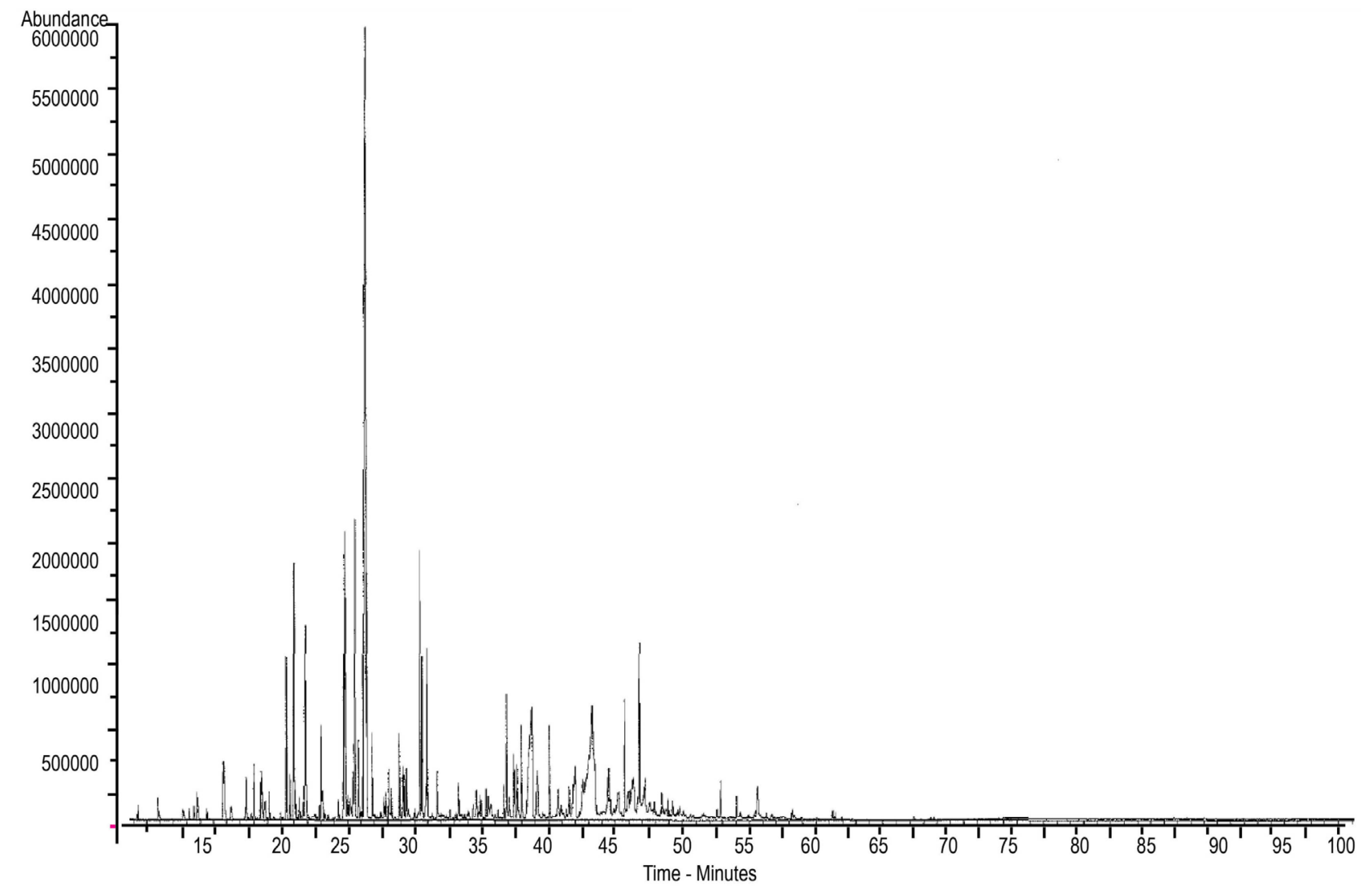

(b) 


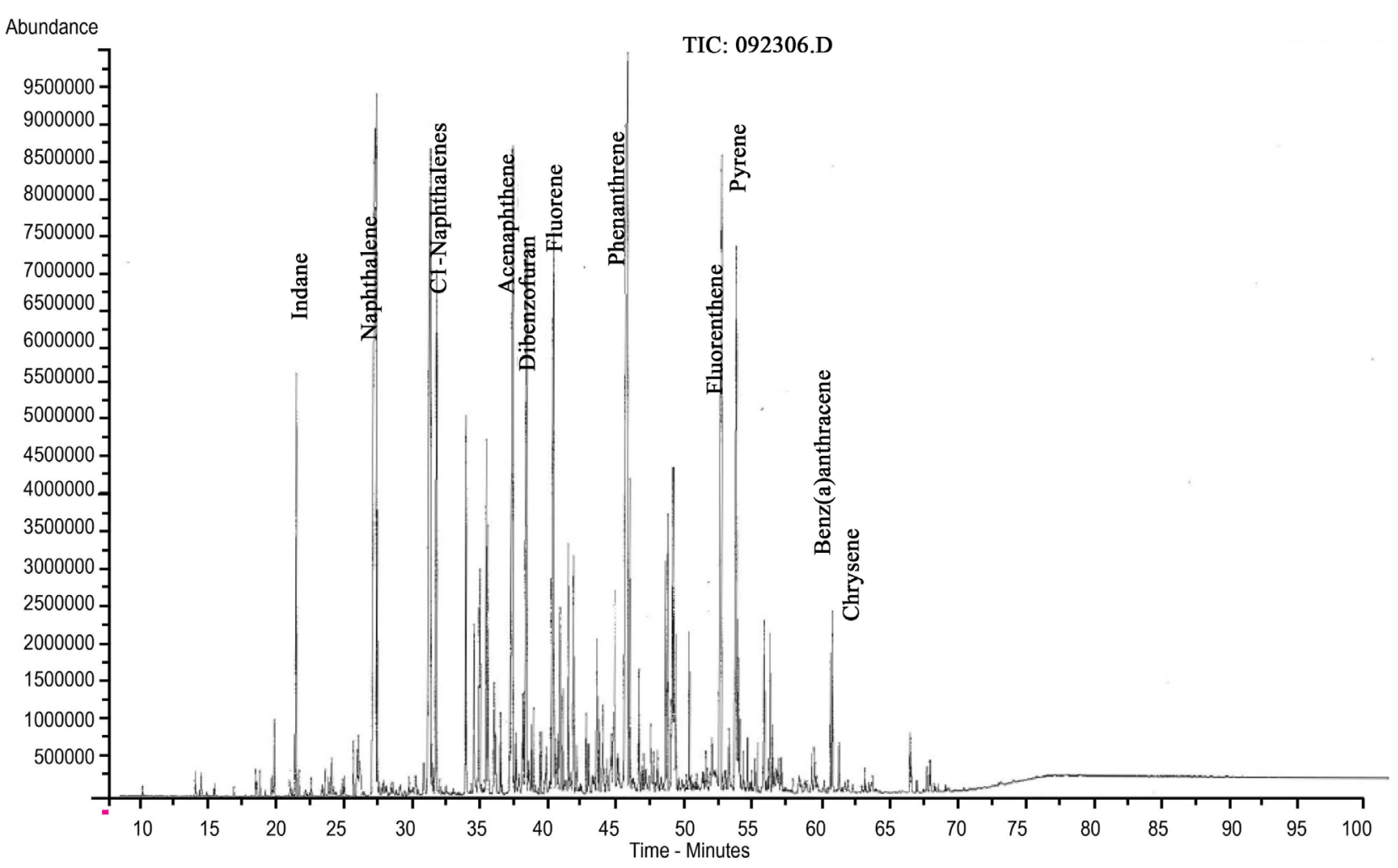

(c)

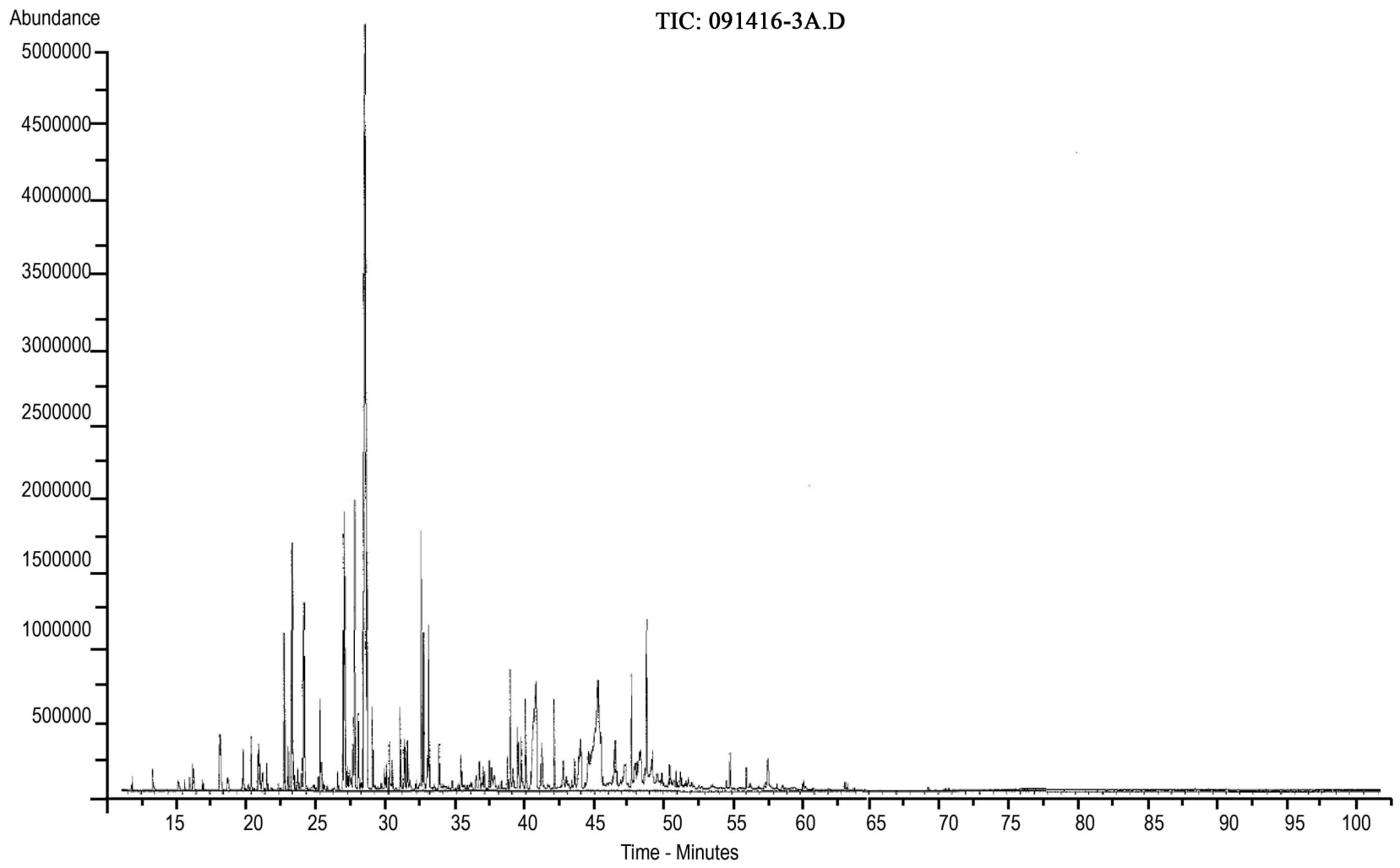

(d)

Figure 4. (a) GC/MS full-scan total ion chromatographs (RS-2/2016); (b) GC/MS full-scan total ion chromatographs (RW-2); (c) GC/MS full-scan total ion chromatographs (MW-11S); (d) GC/MS full-scan total ion chromatographs (MW-11D). 


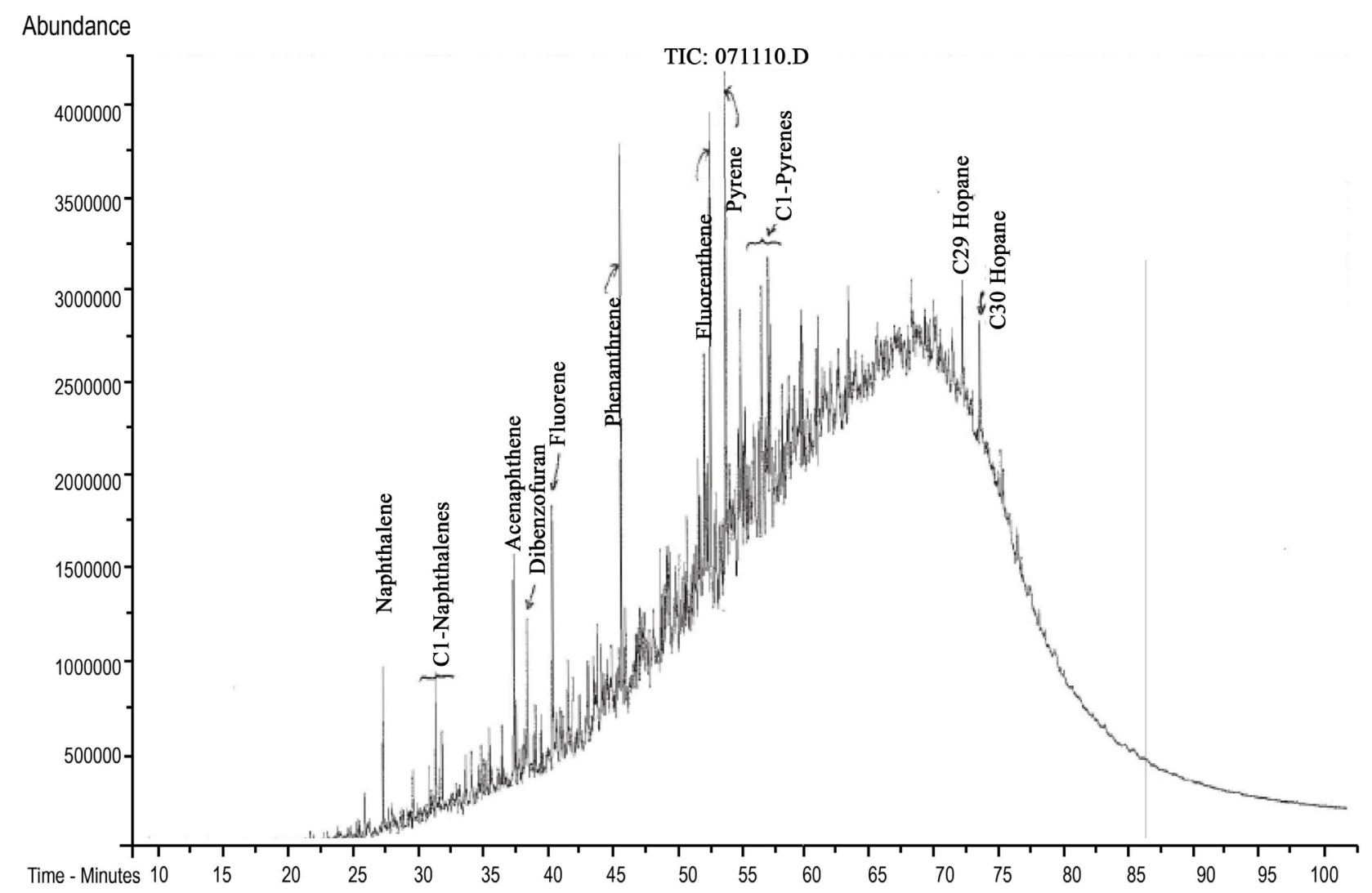

(a)

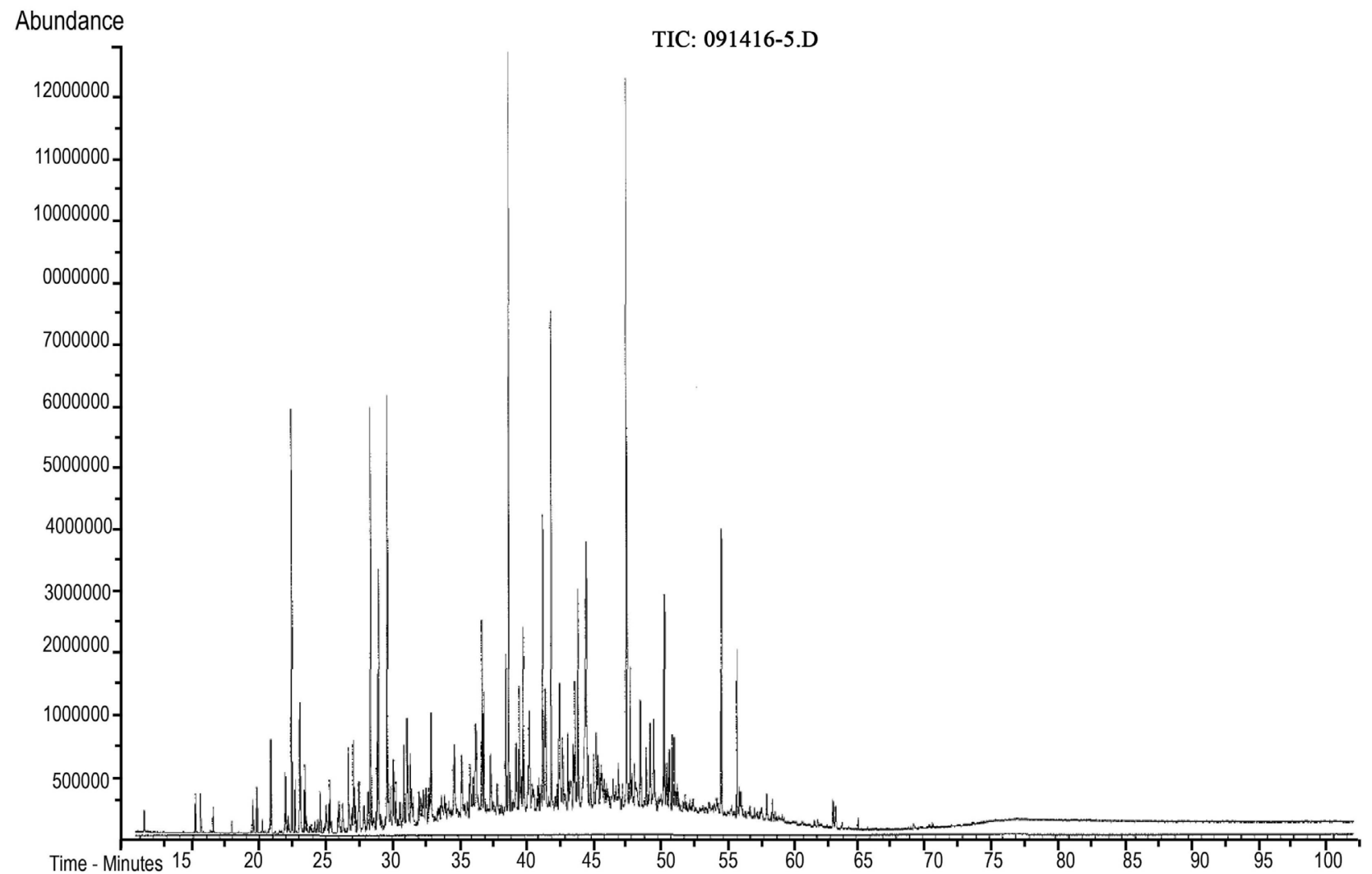

(b) 


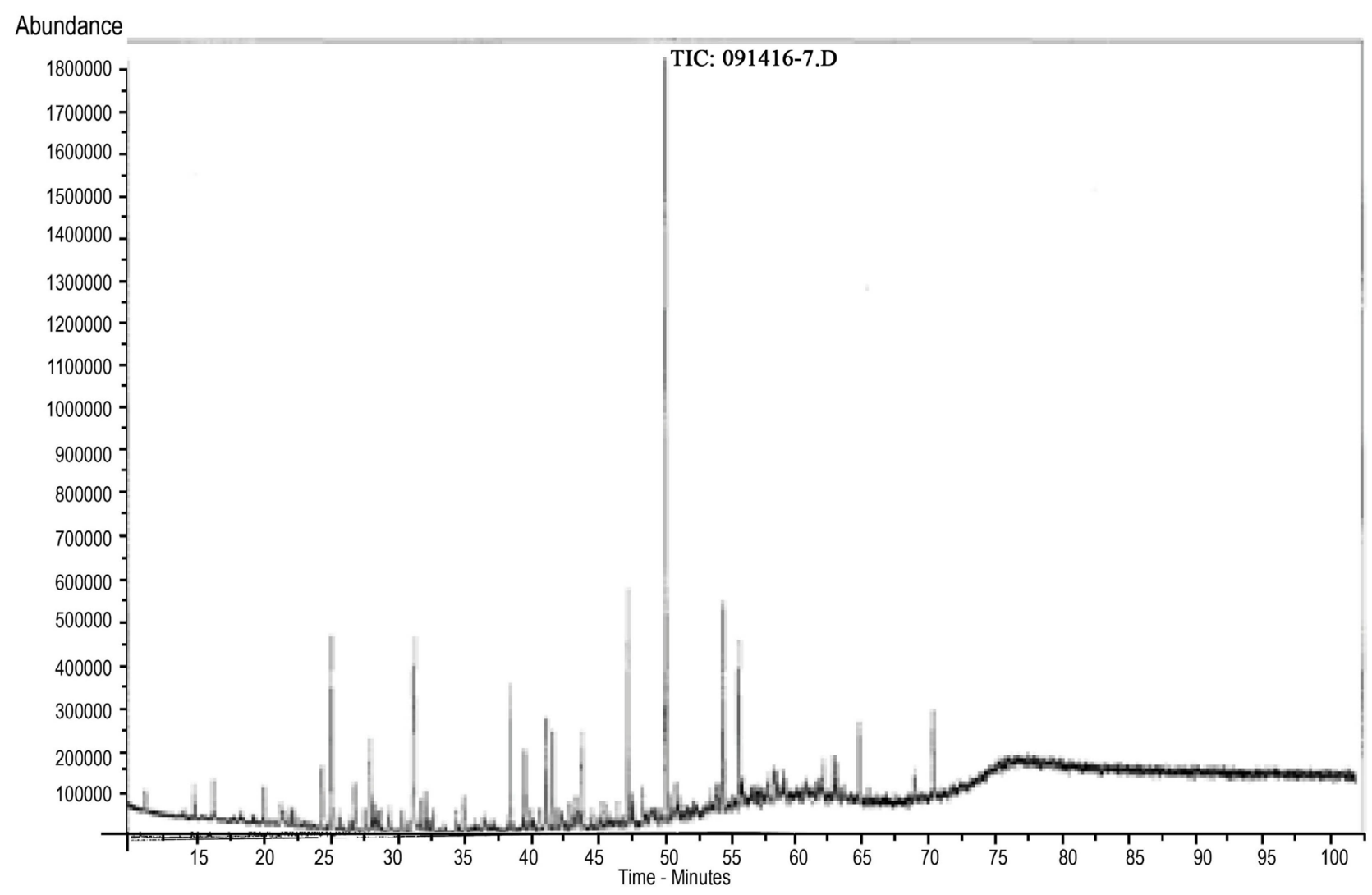

(c)

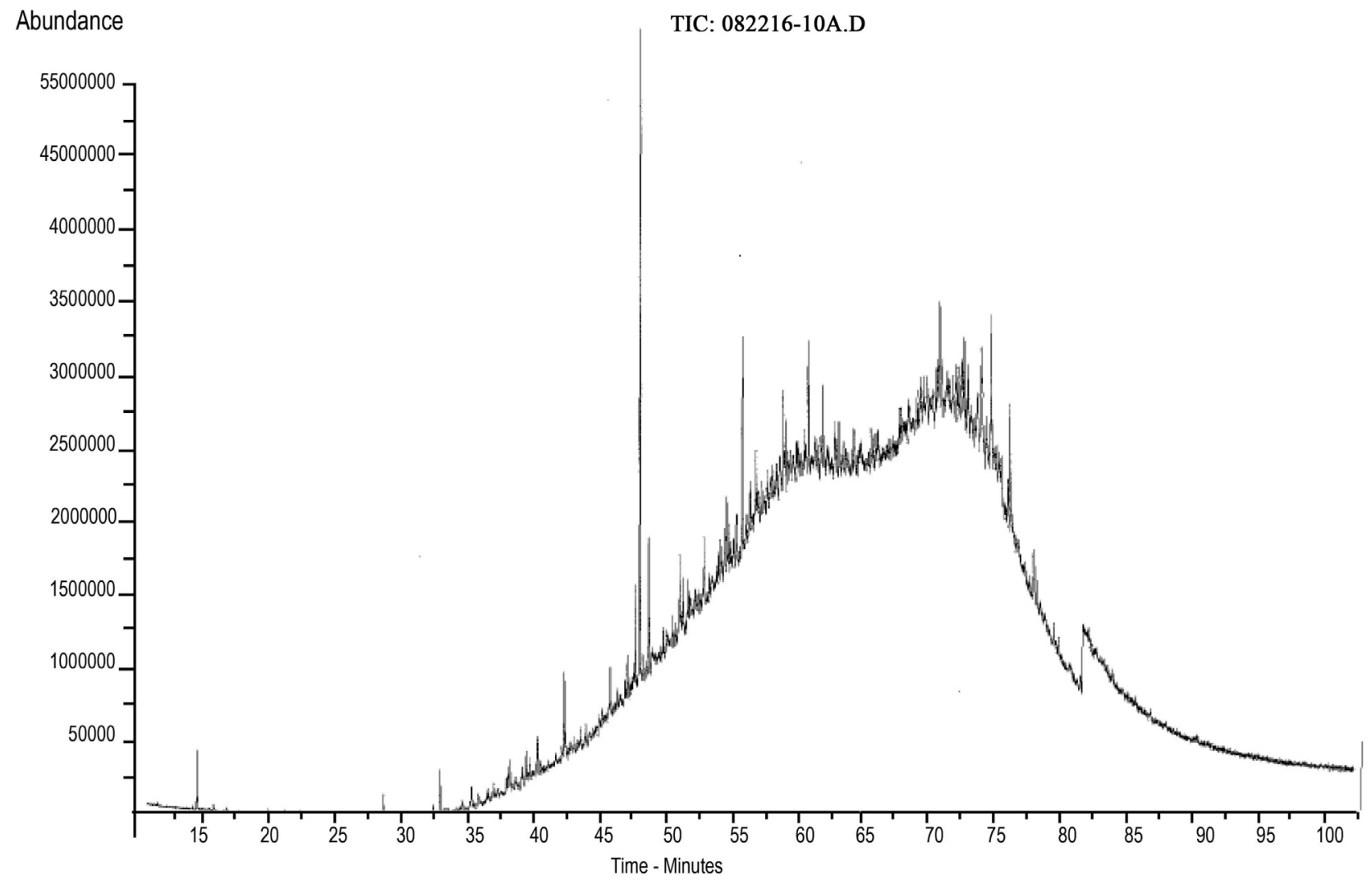

(d) 


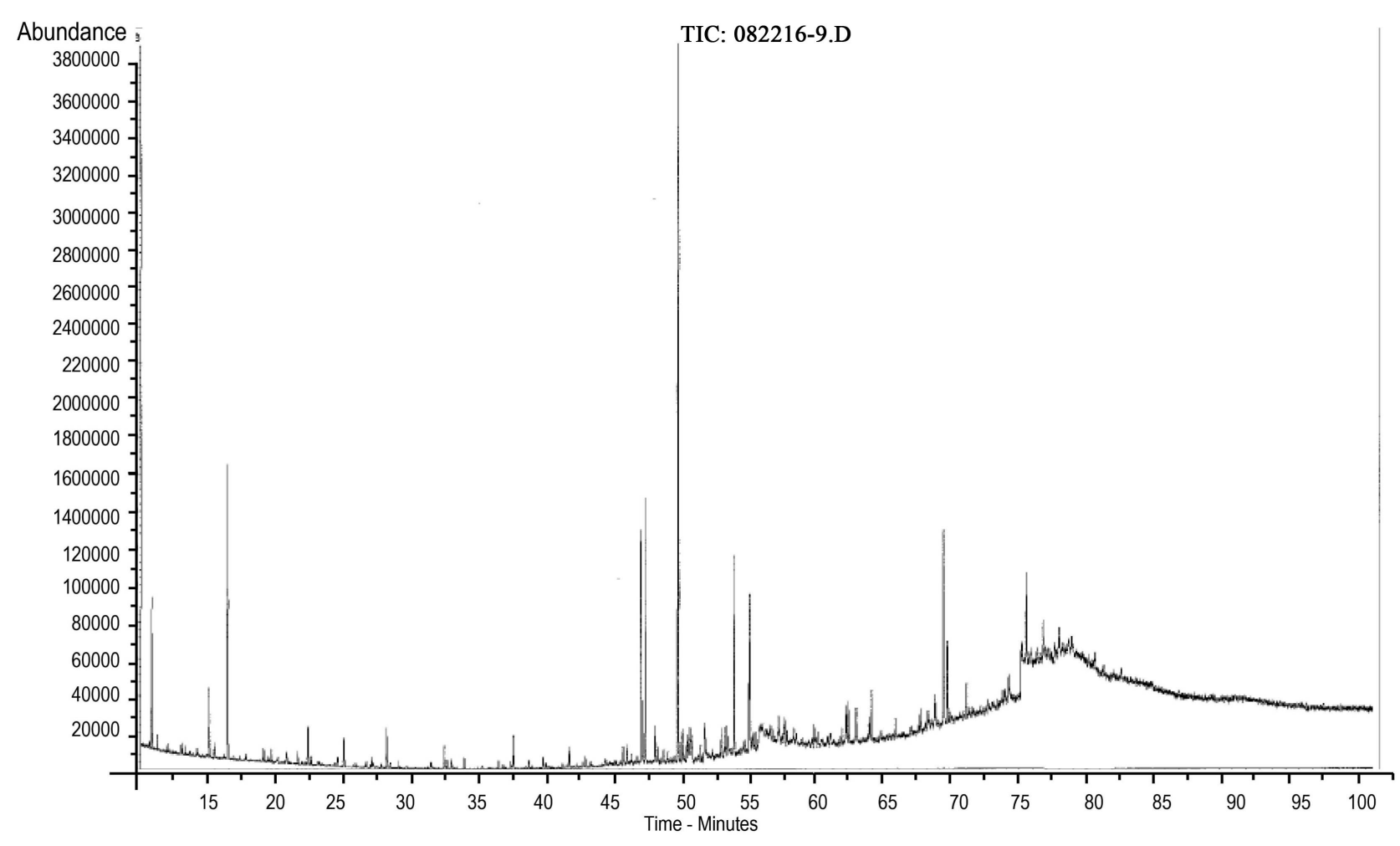

(e)

Figure 5. (a) GC/MS full-scan total ion chromatographs (MW-10S/13); (b) GC/MS full-scan total ion chromatographs (MW-14RS); (c) GC/MS full-scan total ion chromatographs (MW-10S/16); (d) GC/MS full-scan total ion chromatographs (SS-14P); (E) GC/MS full-scan total ion chromatographs (SS-BG).

there are no pattern of biomarkers observed in creosote (Figure 6(c) and Figure 6(d)). The terpane (ion 191profile) and sterane (ion 217 profile) biomarkers in the samples RW-2, MW-11S, and MW-11D (not included) are essentially not present, similar to those of the sample RS-2/2016 (Figure 6(c) and Figure 6(d)) and consistent with creosote signature.

The biomarkers in the samples SS-14P and MW-10S/2013 are shown in Figures 7(a)-(d), respectively. Both terpane and sterane biomarkers are observed to be present, suggesting that these samples contain heavy petroleum products. In samples MW-14RS, MW-10S/2016, and SS-BG (Figure 8(a)-(f)), sterane biomarkers do not appear present (Figure 8(b), Figure 8(d), Figure 8(f), respectively). However, terpane biomarkers appear present with low concentrations (Figure 8(a), Figure 8(c), Figure 8(e), respectively), suggesting the presence of minor amounts of petroleum products in the samples. There are differences in the biomarkers between the sample SS-14P and the sample SS-BG. These differences are discussed in Section 4.0.

\subsection{Gas Chromatography/Mass Spectrometer (GC/MS) Selective Ion Method Polycyclic Aromatic Hydrocarbons (PAH) Analysis}

Eleven samples (RS-2/2013, RS-2/2016, RW-2, MW-10D, MW-10S/2013, MW-11S, 


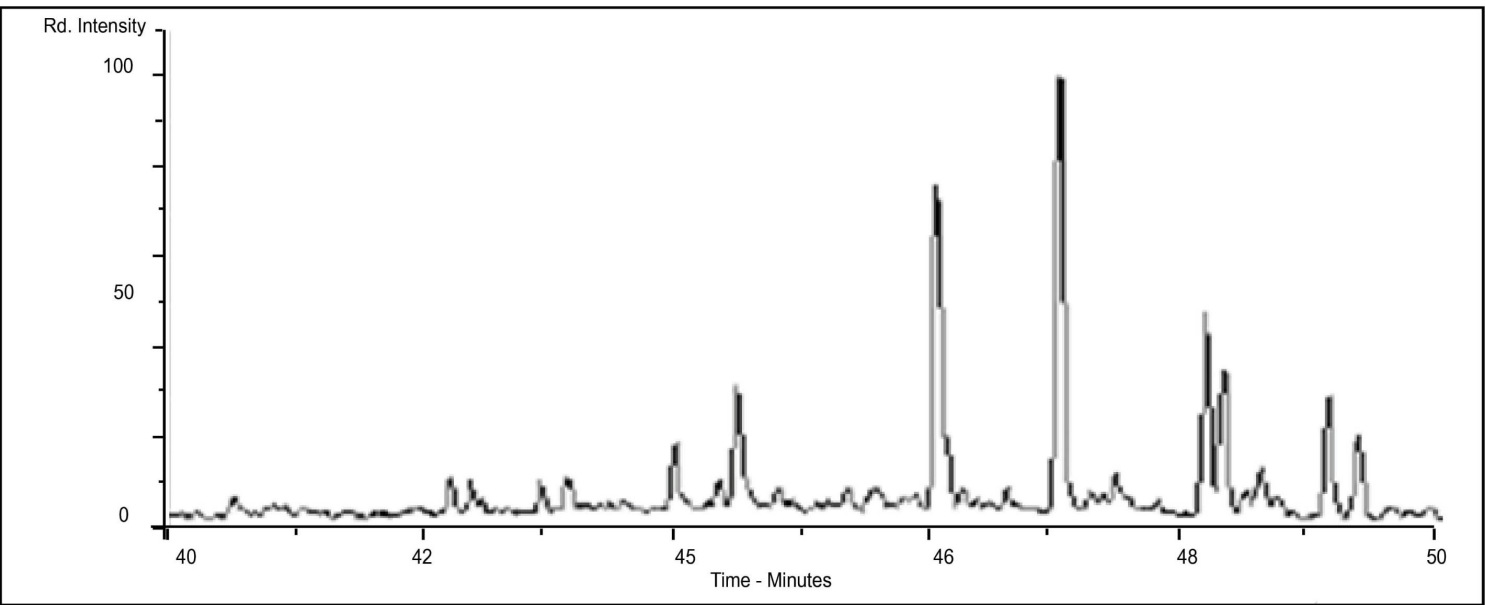

(a)

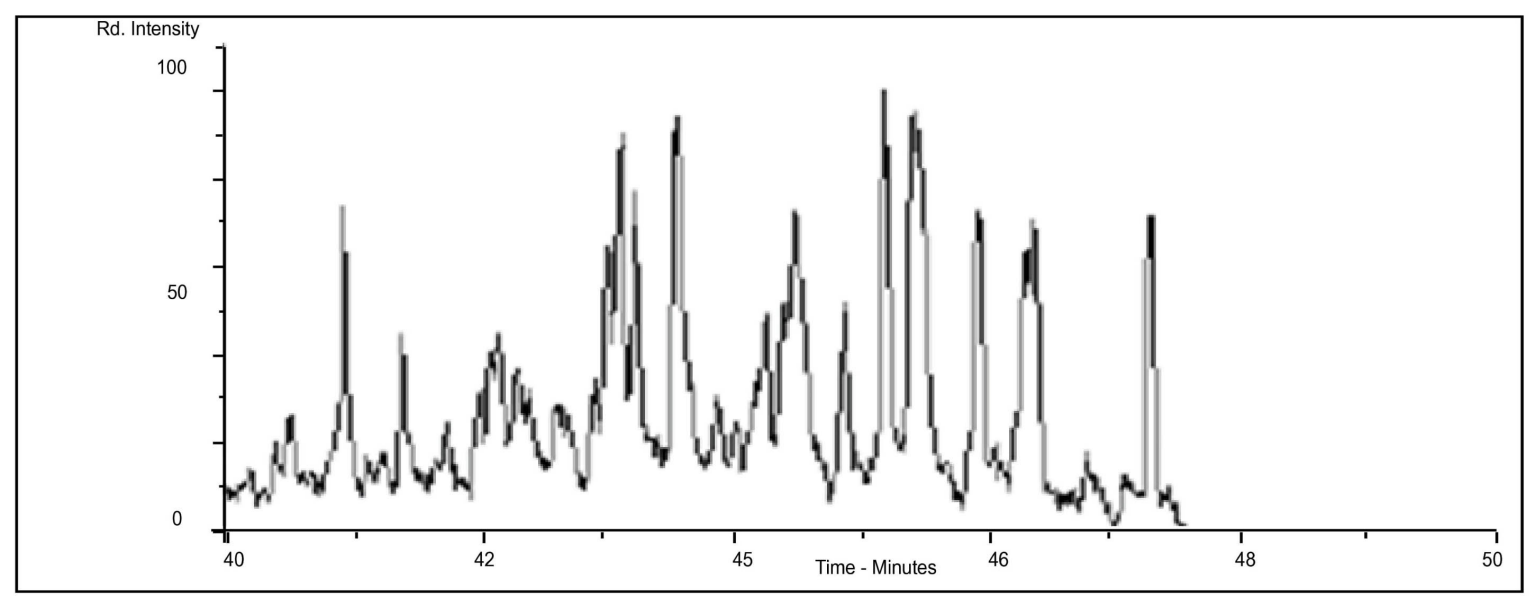

(b)

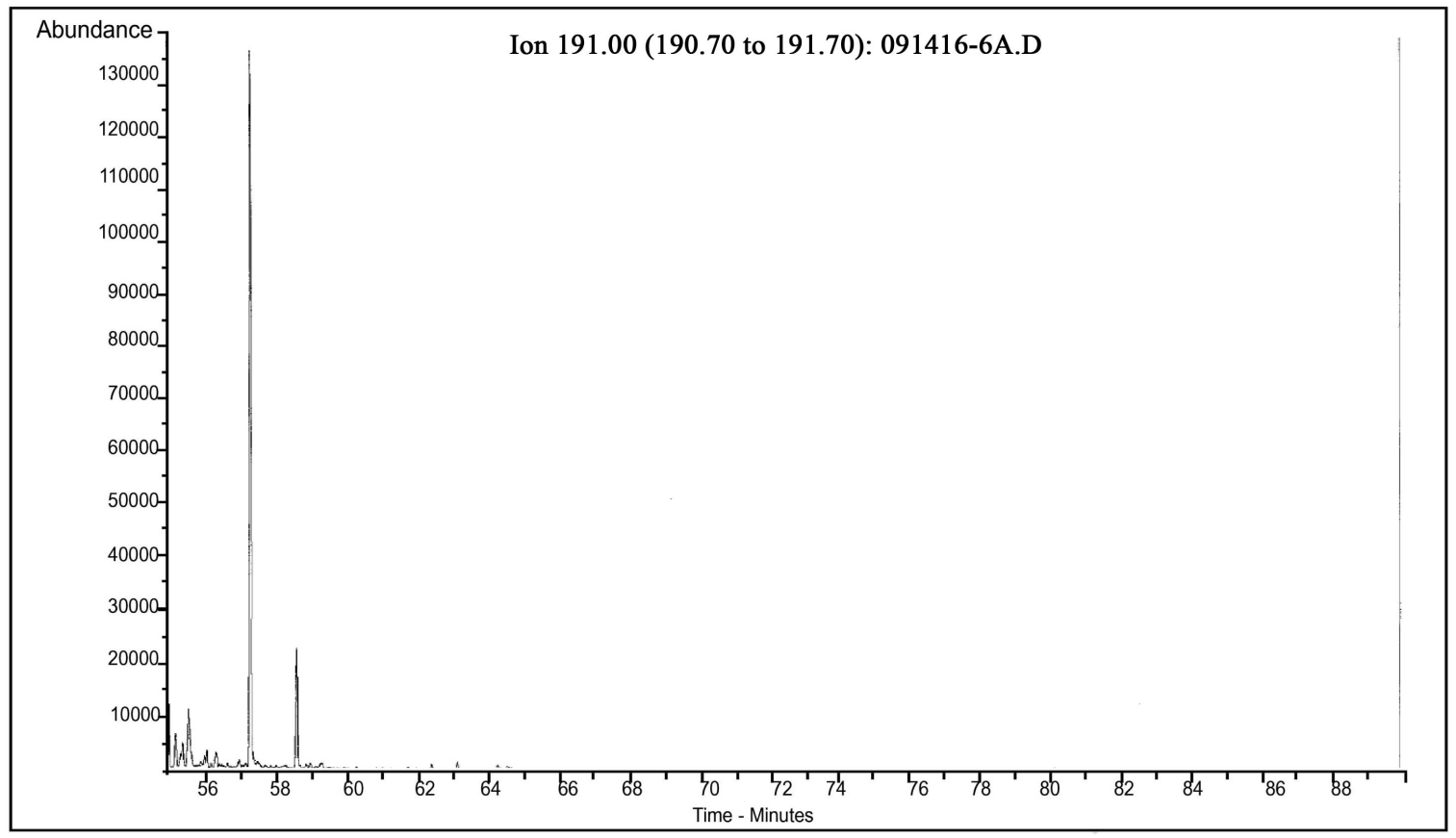

(c) 


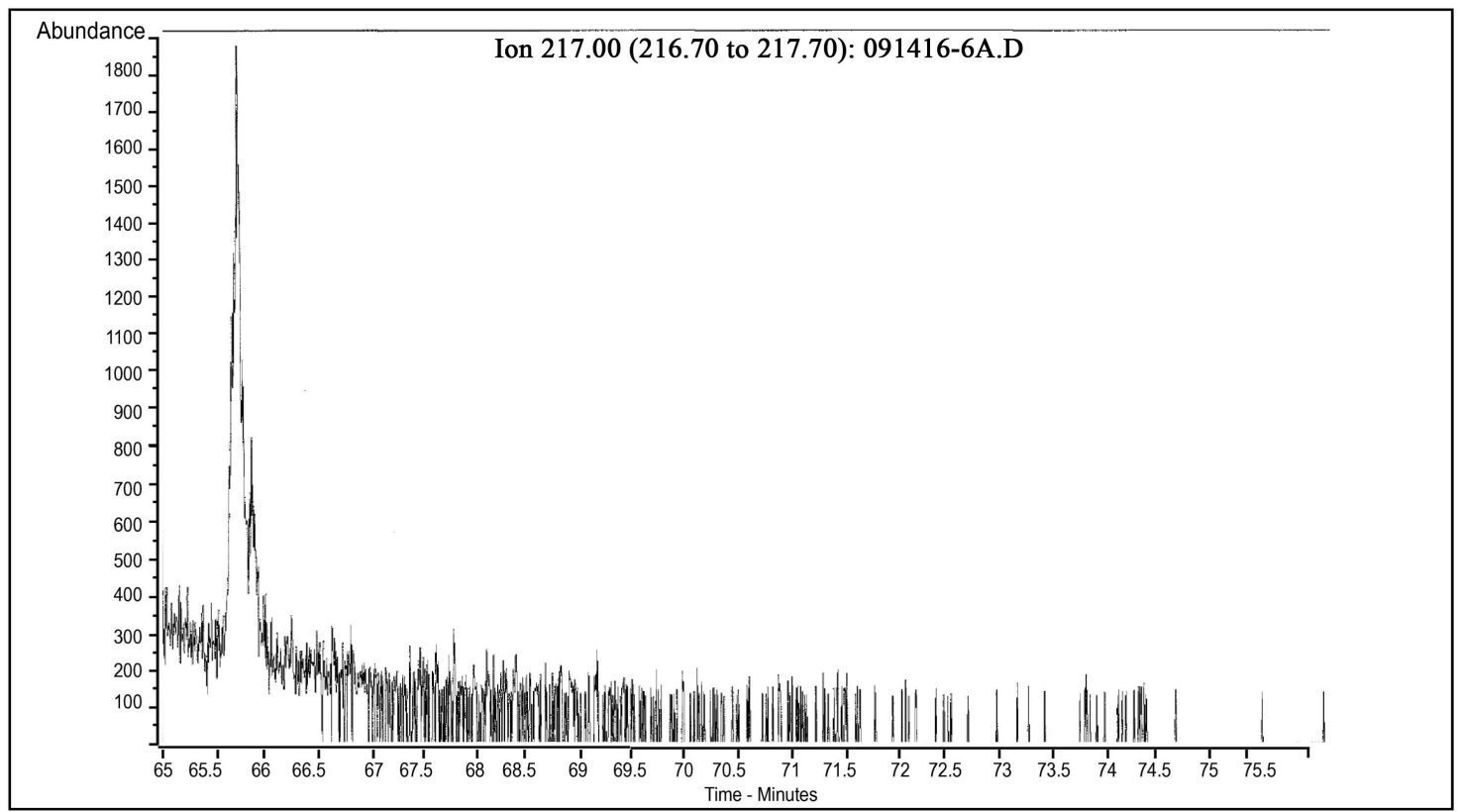

(d)

Figure 6. (a) Mass chromatograms of ion 191 of a type of heavy fuel oil (Dahimann, 2003); (b) Mass chromatograms of ion 217 of a type of heavy fuel oil-after (Dahimann, 2003); (c) Mass chromatograms of ion 191 for creosote (sample RS-2/2016); (d) Mass chromatograms of ion 217 for creosote (sample RS-2/2016). Note that the lines on ion 217 creosote profile are noises, not the peaks of real compounds.

MW-11D, MW-14RS, MW-10S/2016, SS-BG, and SS-14P) were analyzed using this method. Figures 9 (a)-(d) are selected representative histograms (samples RS-2/2013, RS-2/2016, SS-BG and SS-14P). The samplesRS-2/2013, RS-2/2016, and SS-BG show "sloping" pattern in general, indicative of predominantly pyrogenic source, while the sample SS-14P shows a mixture of "sloping" and "bell" patterns, suggesting presence of petrogenic source. The information on sources is generally consistent with chromatographic patterns and biomarker data.

It is well recognized that weathering effects $\mathrm{PAH}$ distributions and can complicate differentiation of pyrogenic and petrogenic sources [3] [4]. In this study, the samples RS-2/2013 are RS-2/2016 provide an opportunity to examine the weathering effect on PAH distribution because they are from the same location collected nearly three years apart. As can be observed Figure 9(a) and Figure 9(b), the sloping patterns are similar to each other in general, but in the naphthalene and phenanthrene homologues, the preferential depletion of parent PAH (naphthalene and phenanthrene) is apparent in the later sample. Also, in the dibenzothiophene homologue, the parent PAH appears to be enriched relative to alkylated PAHs. The differences between samples RS-2/2013 and RS-2/2016 could be a result of blending of the same sources with different proportions, and/or weathering (i.e., with naphthalene and phenanthrene homologues) and the introduction of a new source(s) (i.e., with dibenzothiophene homologue).

$\mathrm{PAH}$ ratios are commonly utilized for differentiating pyrogenic and petrogenic sources and more specific sources with each category [5]-[13]. However, 


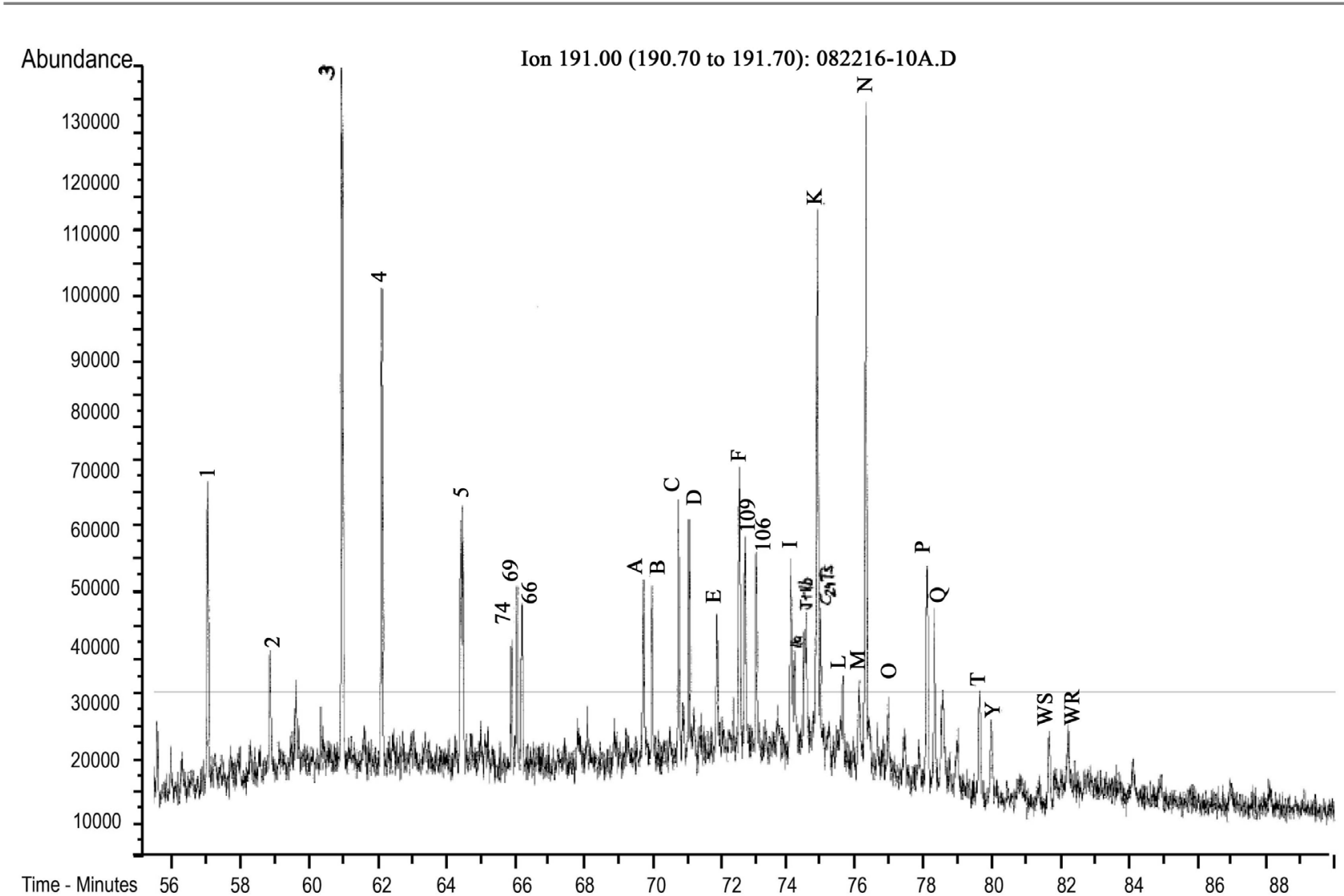

(a)

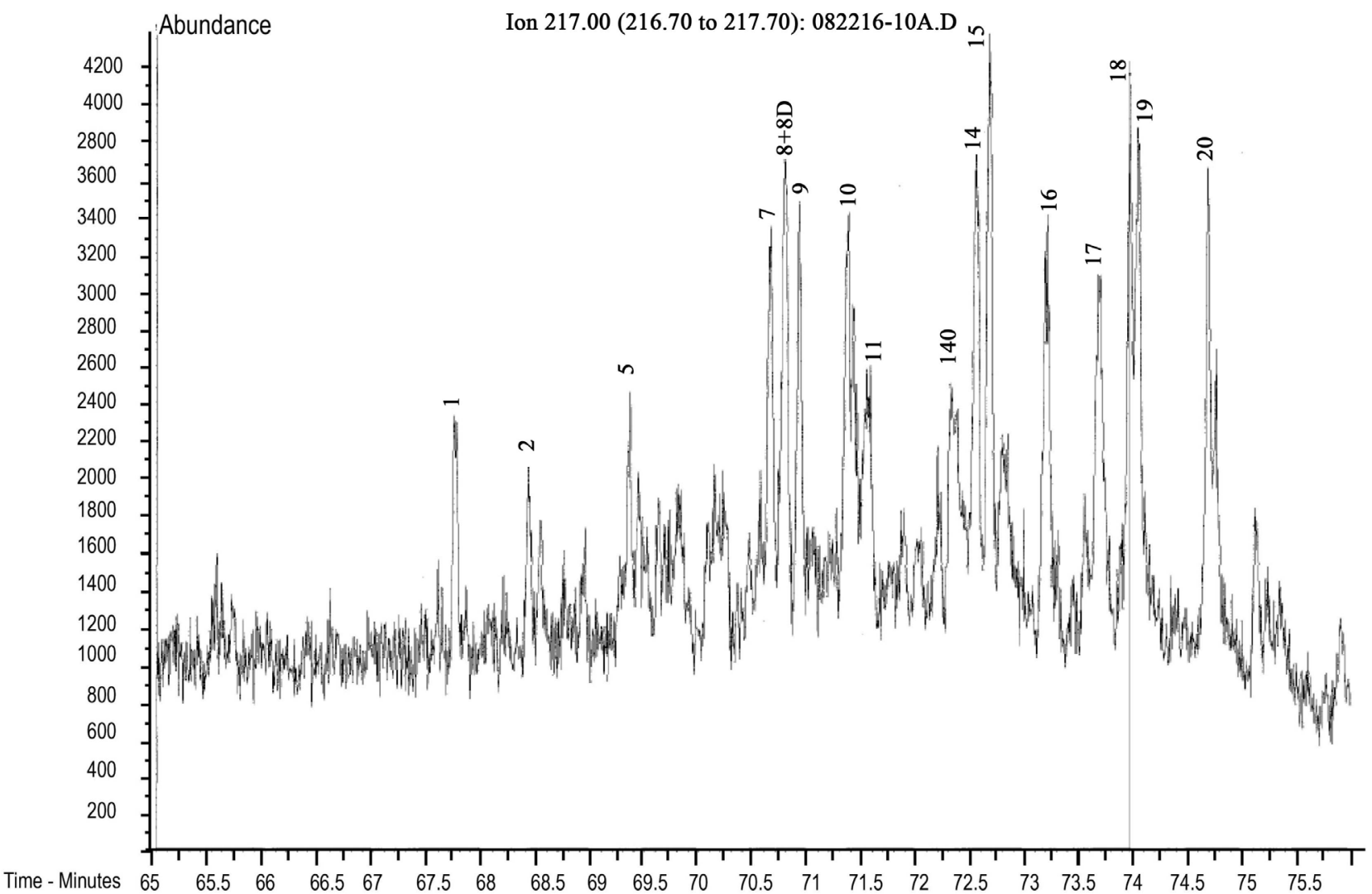

(b) 


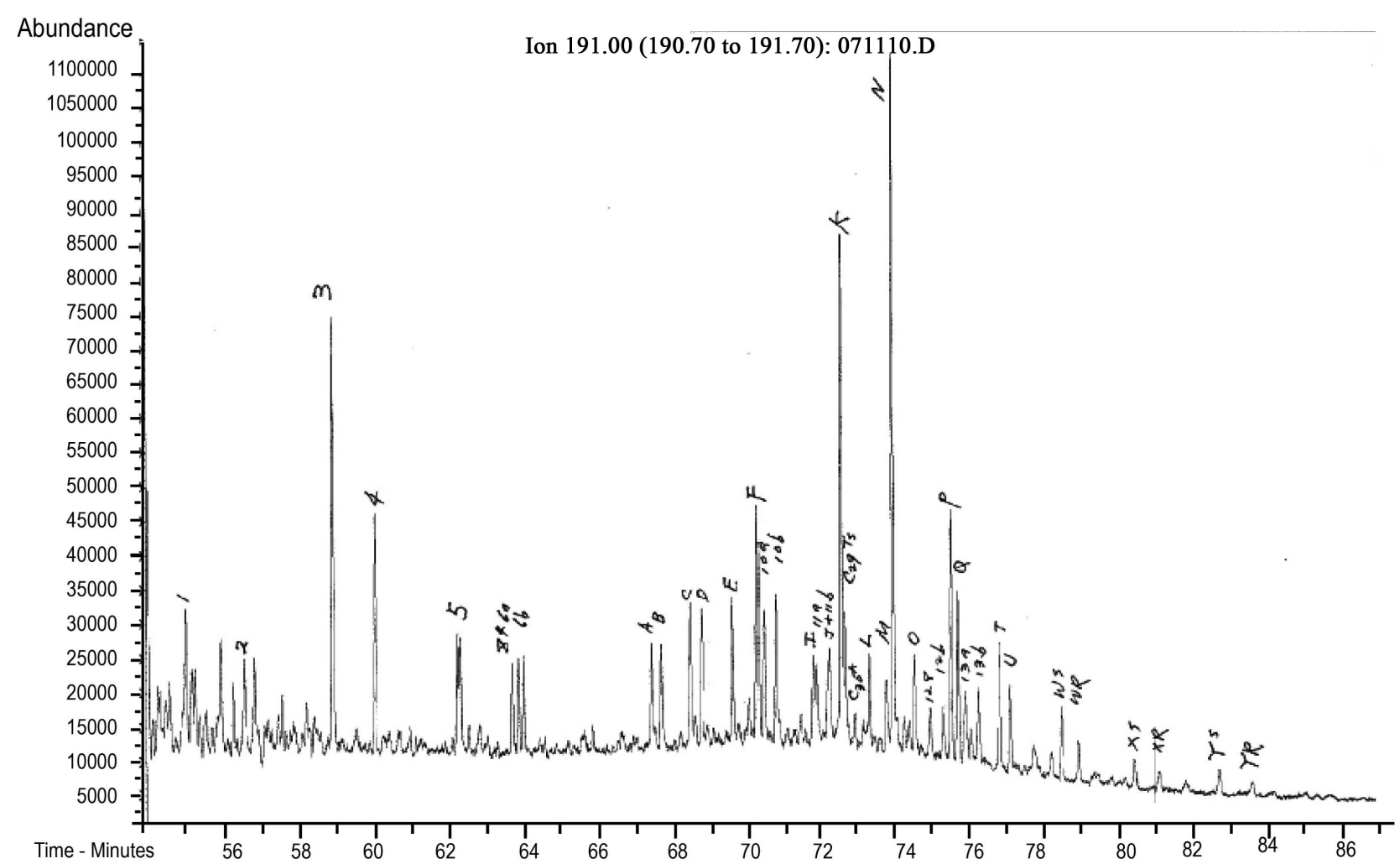

(c)

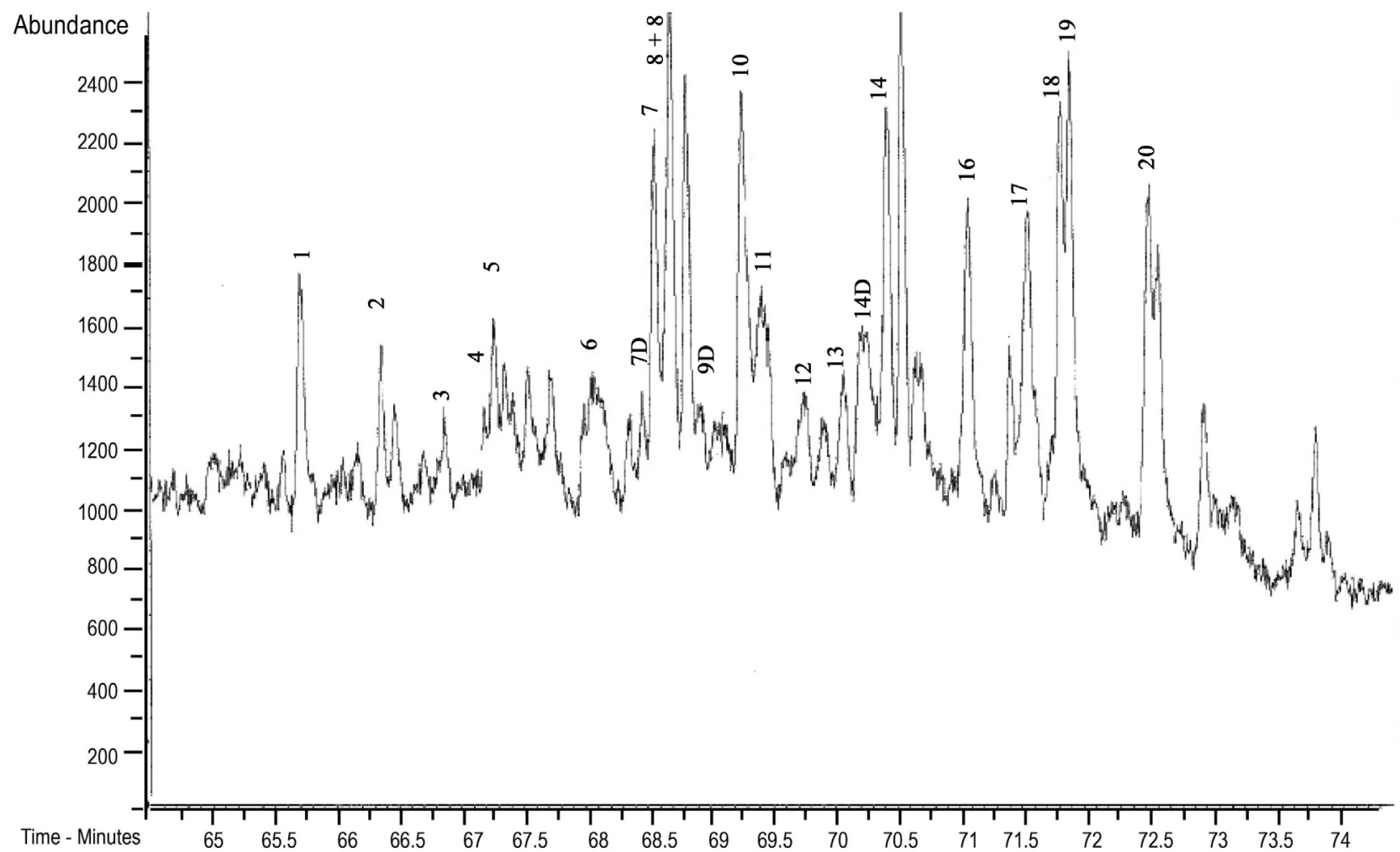

(d)

Figure 7. (a) GC/MS full-scan ion profile 191 (SS-14P); (b) GC/MS full-scan ion profile 217 (SS-14P); (c) GC/MS full-scan ion profile 191 (MW-10S/2013); (d) GC/MS full-scan ion profile 217 (MW-10S/2013). 


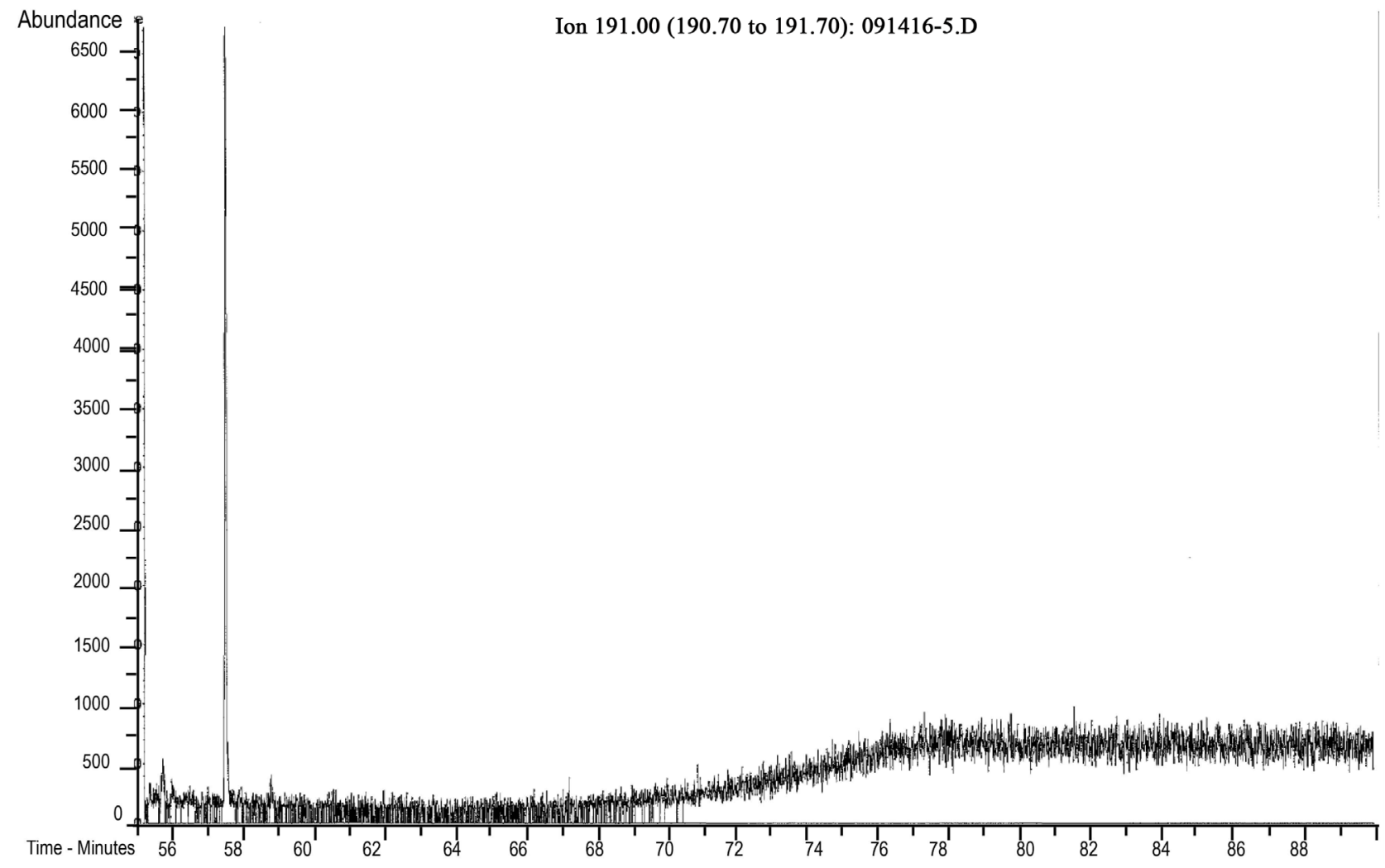

(a)

Abundance

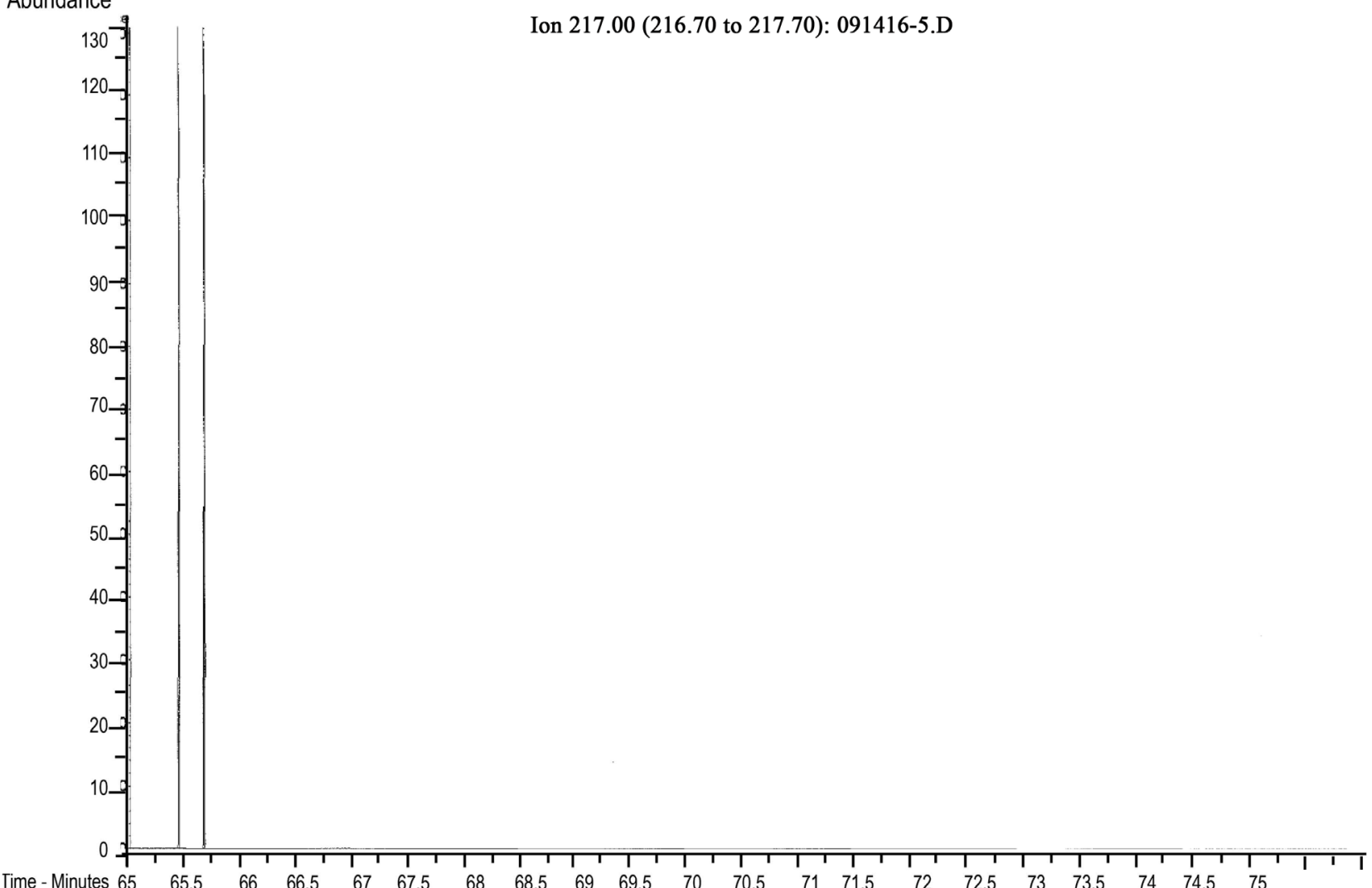

(b) 


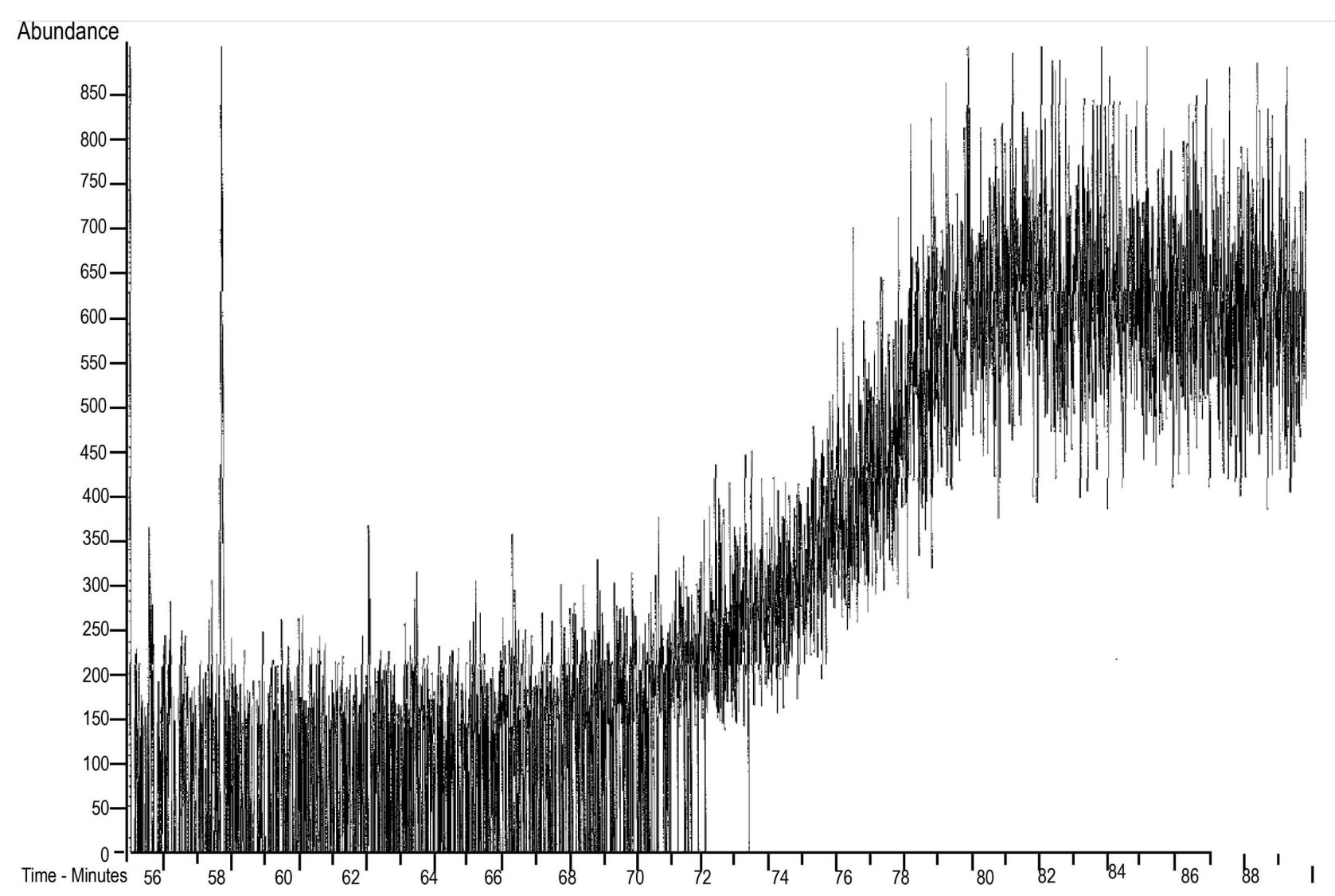

(c)

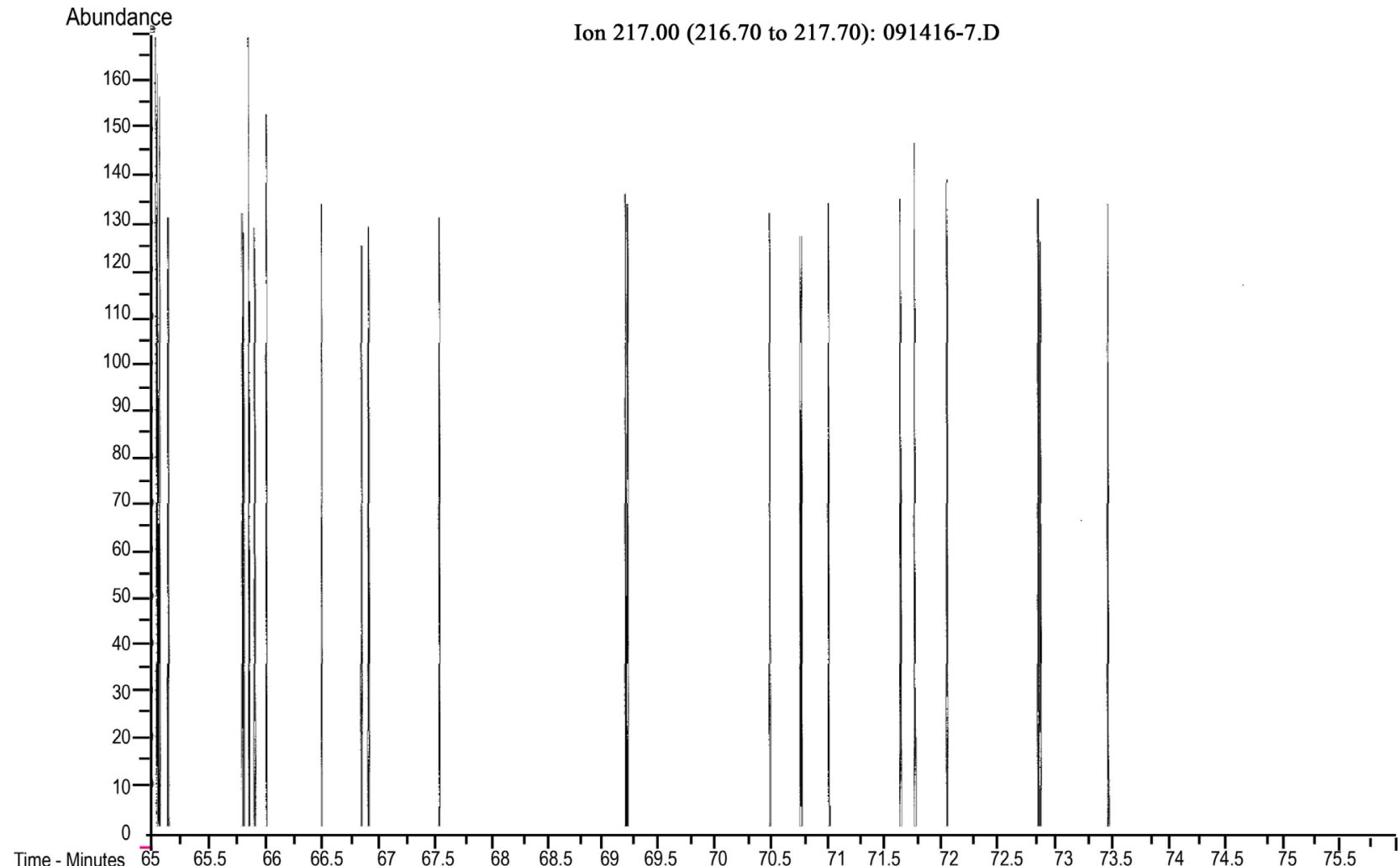

(d) 


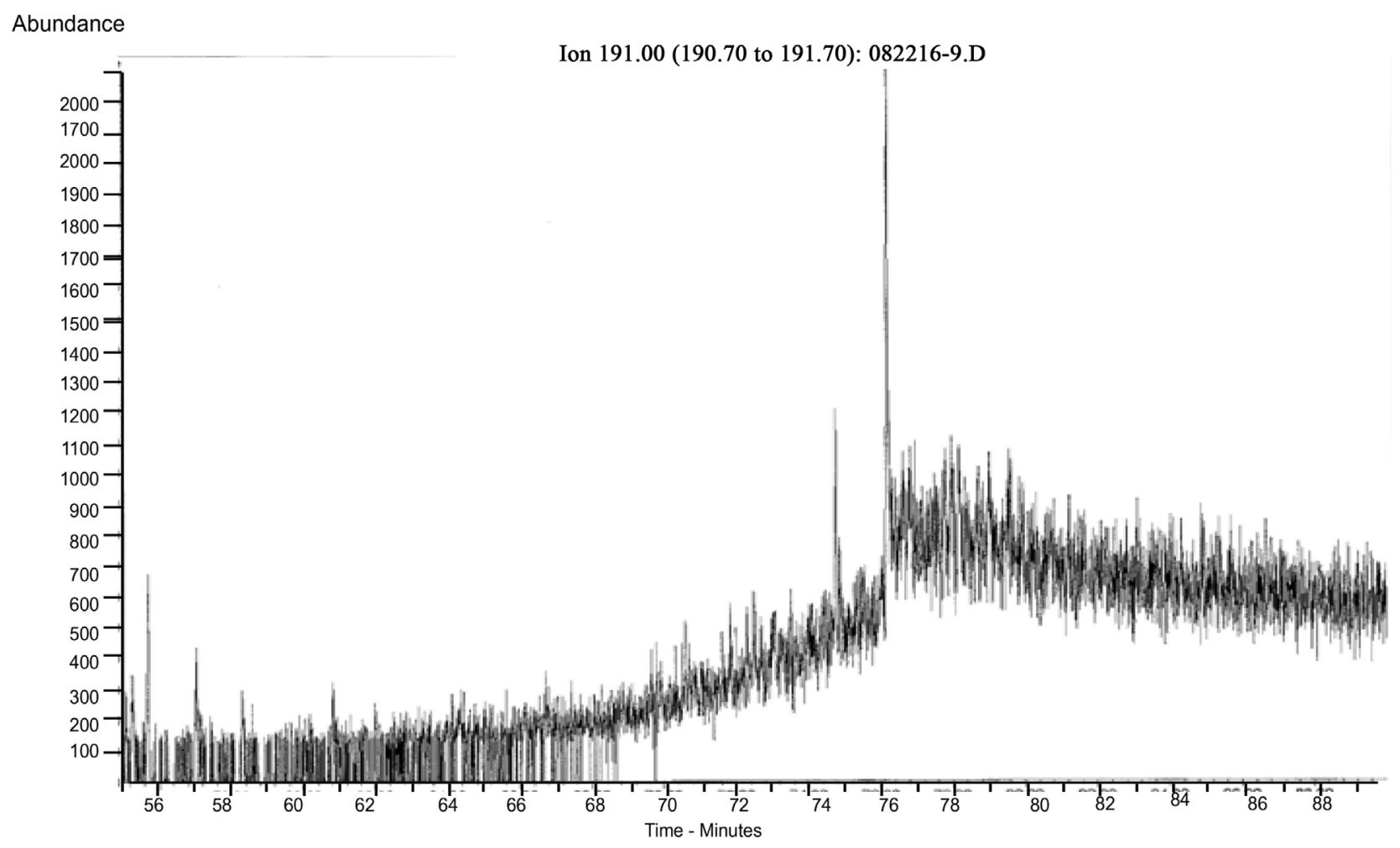

(e)

Abundance

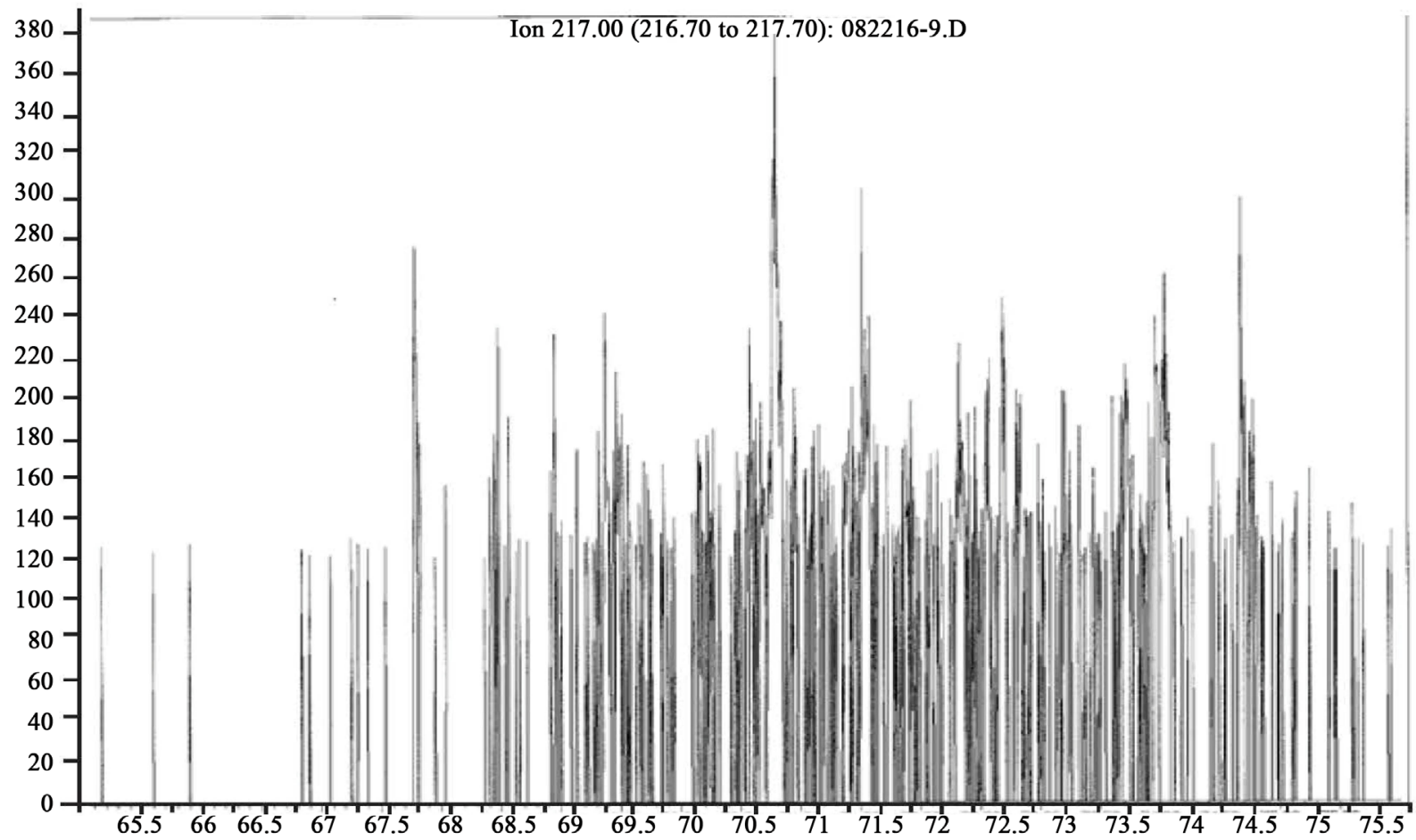

(f)

Figure 8. (a) GC/MS full-scan ion profile 191 (MS-14R); (b) GC/MS full-scan ion profile 217 (MW-14RS); (c) GC/MS full-scan ion profile 191 (MW-10S/2016); (d) GC/MS full-scan ion profile 217 (MW-10S/2016); (e) GC/MS full-scan ion profile 191 (SS-BG); (f) GC/MS full-scan ion profile 217 (SS-BG). 


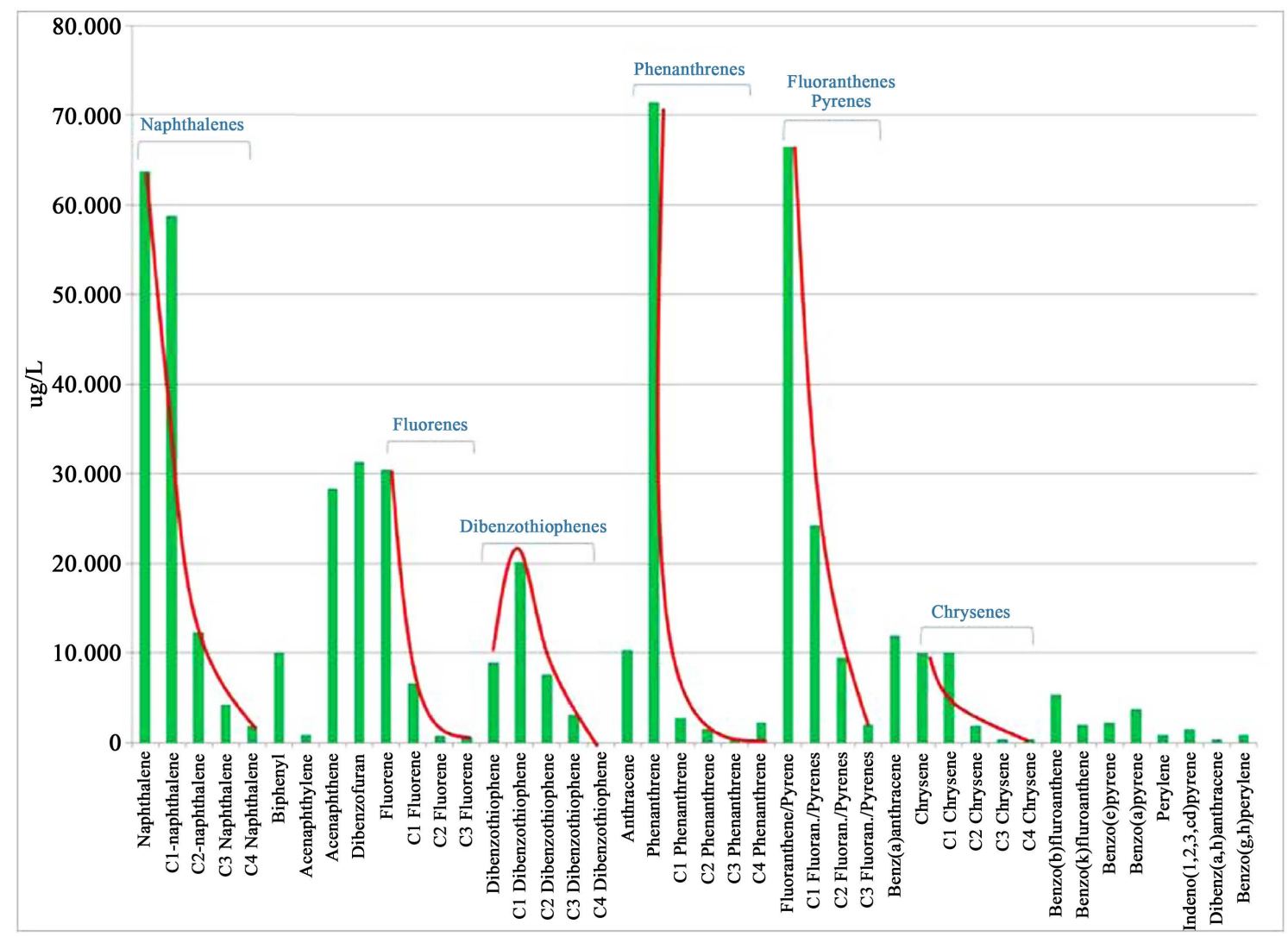

(a)

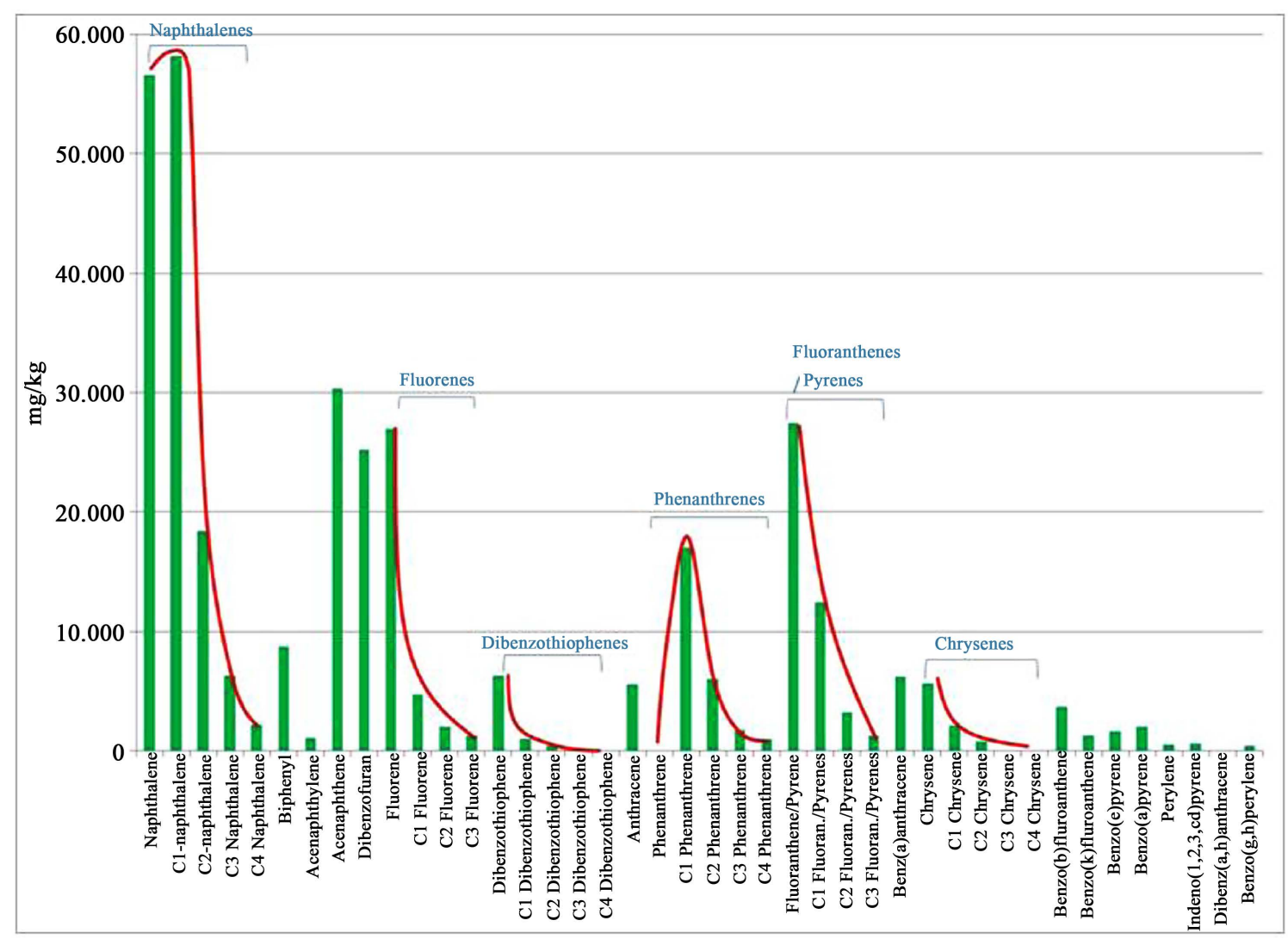

(b) 


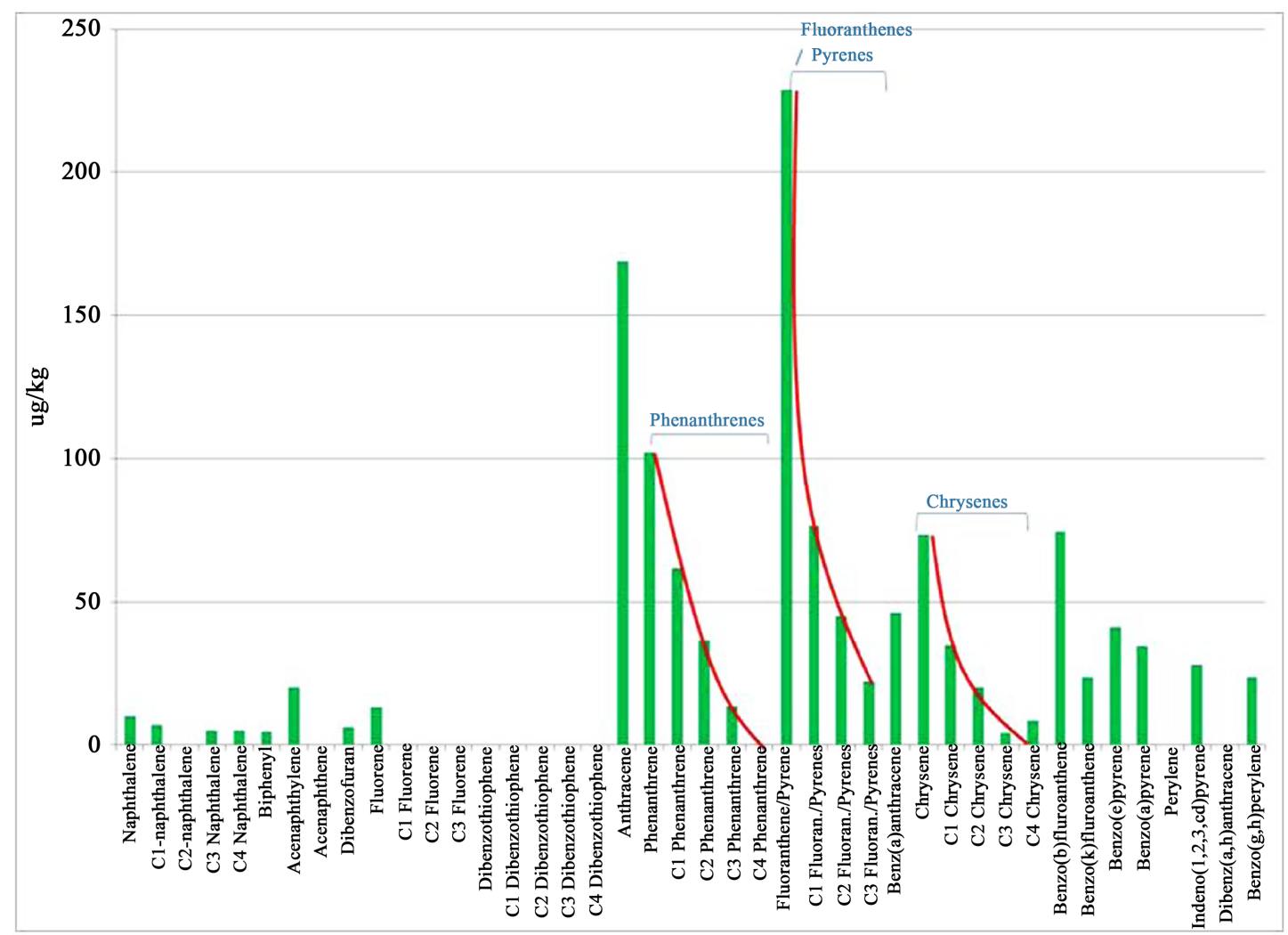

(c)

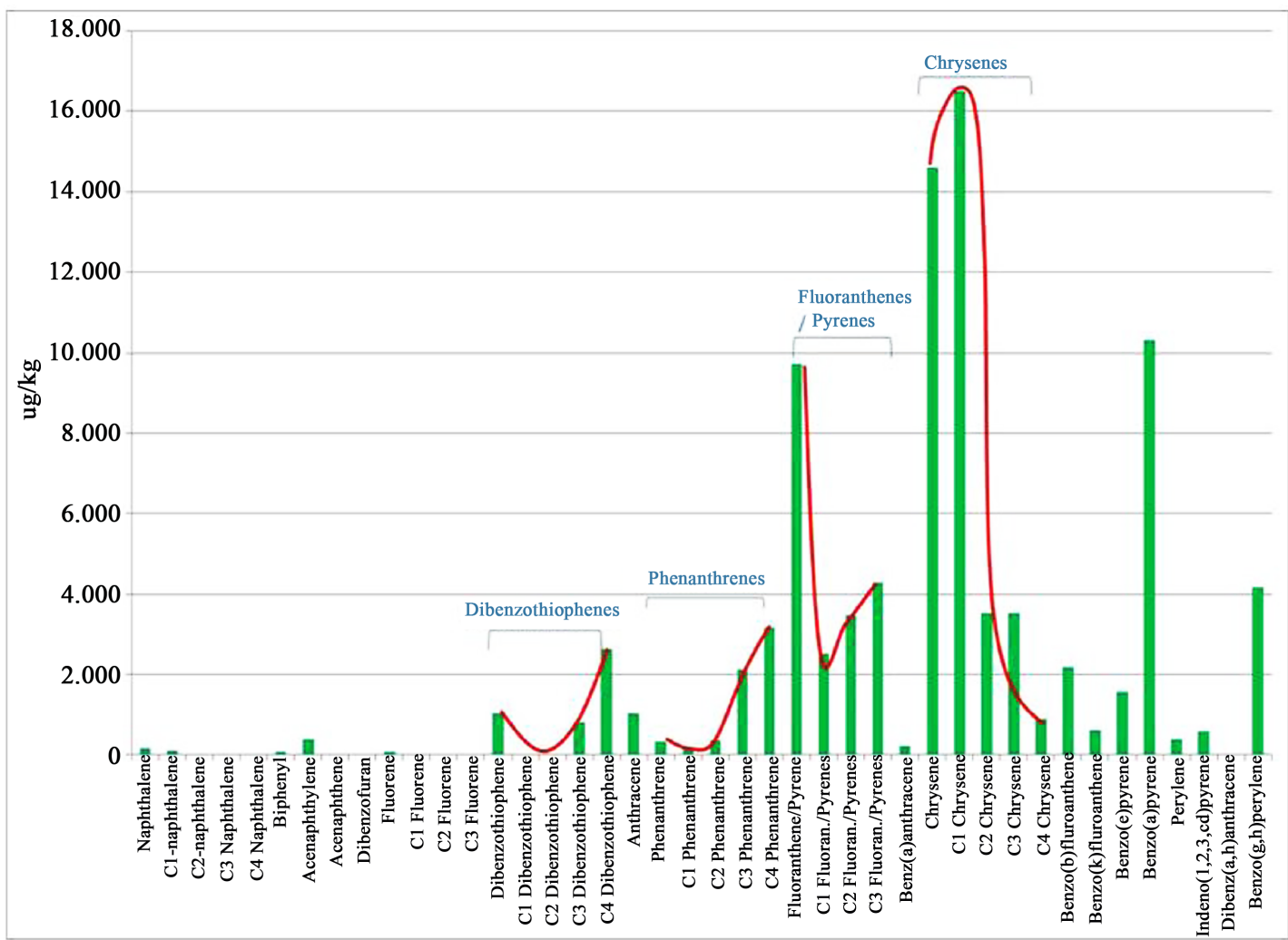

(d)

Figure 9. (a) RS-2/2013 PAH Histogram; (b) RS-2/2016 PAH Histogram; (c) SS-BG PAH Histogram; (d) SS-14P PAH Histogram. 
based on the observations from the samples RS-2/2013 and RS-2/2016, it is apparent that ratio analysis will not provide diagnostic information on sources base on the site specific situation. Given the study objective and highly diagnostic signatures from chromatographic patterns and biomarker data, PAH ratios were not used in this study.

\section{Discussion}

In samples RW-2, RS-2/2013, RS-2/2016, MW-11S, and MW-11D, there are no UCMs discerned from the GC/FID chromatograms and/or GC/MS TICs. In the GC/MS full-scan ion profiles, terpane and sterane biomarkers appear absent. On the PAH histograms, the PAH homologues (i.e., naphthalenes, fluorenes, phenanthrenes, fluoranthenes/pyrenes, chrysenes) exhibit decreasing patterns that typify pyrogenic sources (e.g., creosote) (only histograms for samples RS-2/2013 and RS-2/2016 provided). These samples are creosote without the apparent presence of petroleum products. All this information consistently indicates that heavy petroleum products are either absent or negligible in the samples.

For the sample MW-10D, only GC/FID chromatogram and PAH data are available. The PAH pattern appears pyrogenic (not provided), but the low UCM on the chromatogram indicates the minor presence of petroleum product. As discussed previously, the petrogenic source could well be masked by the dominant pyrogenic source. Therefore, the sample is likely predominantly composed of creosote with minor petroleum product.

In the sample SS-14P, the UCM is prominent from the GC/MS TIC. The terpane and sterane biomarkers on the GC/MS full-scan ion profiles confirm the presence of Fuel No. 6 or similar petroleum product in the sample. The PAH homologues exhibit complex patterns and suggest presence of non-pyrogenic source. All these data together suggest that the sample is composed of a mixture of pyrogenic (creosote) and petrogenic sources (Fuel No.6).

For the samples MW-10S/2013 and MW-10S/2016, GC/MS full scan data (TICs and biomarkers) suggest that both samples contain Fuel No.6 (dominant in the earlier sample; but as a minor component in the later sample). PAH data are also indicative of presence of non-pyrogenic source; but the relative percentage of pyrogenic vs. petrogenic is not consistent with the GC/MS full scan data. While the discrepancy on the relative percentage appears inconclusive, it is not critical for the question of interest. It is likely that the sample contains petroleum product. In sample MW-14RS, there is presence of UCM on the TIC, complex $\mathrm{PAH}$ homologues on the PAH histogram (not provided) and potentially low concentrations of terpane biomarkers. These data together suggest that the sample is predominantly composed of creosote; but likely contains minor amounts of heavy petroleum products.

In sample SS-BG, the PAH patterns suggest that the sample is pyrogenic in nature; however, the UCM in the heavier hydrocarbon range from the GC/MS TIC and potential low concentrations of terpane biomarkers suggest the minor presence of heavy petroleum hydrocarbons in the sample. As discussed pre- 
viously, PAH signature of minor petrogenic products may well be masked by the dominant pyrogenic products. Therefore, it is likely that the sample is predominantly composed of weathered creosote with minor heavy petroleum hydrocarbons.

It should be noted that while the both soil samples (SS-14P and SS-BG) contain heavy petroleum hydrocarbons, the nature of the hydrocarbons appears distinctly different and is reflected on the PAH patterns, GC/MS TICs, and most importantly terpane and sterane biomarkers. The differences consistently suggest that the hydrocarbons in the sample SS-BG are heavier and/or more weathered than those in the sample SS-14P.

The minor presence of petroleum product in shallow subsurface soil (SS-BG) is due to the industrial use at the Site and surrounding properties, as noted in Section 1.0. The soil sample SS-BG was advanced next to monitoring well pair MW-12S/D which is an established "background" well pair for the Site. The groundwater samples collected from this well pair have had trace detections of ethylbenzene and toluene below the sample reporting limits (shallow well, only) and trace levels of PAHs related to creosote. No dissolved constituents have been reported above the Site-specific risk reduction standards (and no NAPL (light or dense) observed in this well pair. Any petroleum constituents present in that shallow surface soil sample are representative of background conditions resulting from decades of industrial use.

\section{Conclusions}

The samples RS-2/2013, RS-2/2016, RW-2, MW-11D, and MW-11S were collected from locations where DNAPL believed to be primarily creosote was consistently measured. The interpretation derived from the laboratory analytical results supports the conclusion that these samples are creosote without petroleum impacts. The samples collected near the Site property lines (samples SS-14P, MW-10S/2013, and MW-10S/2016) are composed of a mixture of Fuel No. 6 or similar petroleum product and weathered creosote. Samples MW-14RS and MW-10D are composed of a mixture of predominantly creosote and potentially minor Fuel No. 6 oil/similar petroleum product.

The background soil sample SS-BG is predominantly composed of weathered creosote with potentially minor heavy petroleum hydrocarbons. The minor presence of petroleum is typical of background conditions in an area with long-term heavy industrial use.

The creosote and petroleum facilities are very close to one another and have operated for decades, resulting in suspected product co-mingling along property boundaries. These results and their associated sample locations and proximity to known releases, support the differentiation of petroleum and creosote-derived products. The combined interpretation of dissolved plume characteristics, Site hydraulic influences, and these results provide several lines of evidence to support remediation design and performance monitoring, and liability allocation among potentially responsible parties. 


\section{References}

[1] Youngblood, W.W. and Blumer, M. (1975) PAHs in the Environment: Homologous Series in Soils and Recent Marine Sediments. Geochimicaet Cosmochimica Acta, 39, 1303-1314.

[2] Hites, R.A., Laflamme, R.E. and Farrington, J.W. (1977) Sedimentary PAHs: The Historical Record. Science, 198, 829-831.

[3] Boehm, P.D. (2006) PAHs. In: Morrison, R.D. and Murphy, B.L., Eds., Environmental Forensics_Contaminant Specific Guide, Academic Press, Boston, pages.

[4] Brenner (2002) Characterization and Fate of PAH-Contaminated Sediments at the Wycoff/Eagle Harbor Superfund Site. Environmental Science and Technology, 36, 2605-2613.

[5] Gschwcnd, P.M. and Hites, R.A. (1981) Fluxes of Polycyclic Aromatic Hydrocarbons to Marine and Lacustrine Sediments in the Northeastern United States. Geochemicaet Cosmochimica Acta, 45, 2359-2367.

https://doi.org/10.1016/0016-7037(81)90089-2

[6] Boehm, P.D. and Farrington, J.W. (1984) Aspects of the Polycyclic Aromatic Hydrocarbon Geochemistry of Recent Sediments in the Georges Bank Region. Environmental Science and Technology, 18, 840-845.

[7] Garrigues, P., Budzinski, H., Manitz, M.P. and Wise, S.A. (1995) Pyrolytic and Petrogenic Inputs in Recent Sediments: A Definitive Signature through Phenanthrene and Chrysene Compound Distribution. Polycyclic Aromatic Compounds, 7, 275-284. https://doi.org/10.1080/10406639508009630

[8] Budzinski, H., Jones, J., Bellocq, C., Pierard, C. and Garrigues, P. (1997) Evaluation of Sediment Contamination by Polycyclic Aromatic Hydrocarbons in the Gironde Estuary. Marine Chemistry, 58, 85-97. https://doi.org/10.1016/S0304-4203(97)00028-5

[9] Kennicutt II, M.C. (1998) The Effect of Biodegradation on Crude Oil Bulk and Molecular Composition. Oil and Chemical Pollution, 4, 89-112. https://doi.org/10.1016/S0269-8579(88)80014-5

[10] Dickhut, R., Canuel, E., Gustafson, K., Liu, K., Arzayus, K., Walker, Edgecombe, G., Gaylor, M. and Macdonald, E. (2000) Automotive Sources of Carcinogenic Polycyclic Aromatic Hydrocarbons Associated with Particulate Matter in the Chesapeake Bay Region. Environmental Science and Technology, 34, 4635-4640. https://doi.org/10.1021/es000971e

[11] Emsbo-Mattingly, S. and Boehm, P.D. (2003) Identifying PAHs from Manufactured Gas Plant Sites. Technical Report No. 1005289, Electric Power Research Institute, Palo Alto.

[12] Page, D.S., Bence, A.E., Burns, W.A., Boehm, P.O., Brown, J.S. and Douglas, G.S. (2002) Holistic Approach Tohydrocarbon Source Allocation in the Subtidal Sediments of Prince William Sound Embayments. Journal of Environmental Forensics, 3, 331-340. https://doi.org/10.1080/713848391

[13] Costa, H.J. and Sauer, T.C. (2005) Forensic Approaches and Considerations in Identifying PAH Background. Environmental Forensics, 6, 9-16.

https://doi.org/10.1080/15275920590913859 